\title{
Engineering Foundation Conference Advances in Optics for Biotechnology, Medicine, and Surgery Kona Surf Resort and Conference Center, Kailua-Kona, Hawaii August 1-6, 1999 \\ Final Report
}

\section{Conference Chairs:}

Eva Sevick-Muraca, formerly of Purdue University, West Lafayatte, $\mathbb{N}$

Arjun Yodh, University of Pennsylvania, Philadelphia, PA

David Benaron, Stanford University, Stanford, CA

The intent of the conference was to gather a group of cross-disciplinary investigators from universities, medical schools, national laboratories, industry, and government in order to highlight future applications and technology of the optical sciences in biotechnology, medicine, and surgery. The session chairs organized a spectacular conference and brought new participants and speakers to the conference who were not regular attendees of the OSA and SPIE conferences. Attendees included a good number of graduate and post-doctoral students who tended to join the more senior members in organized and spontaneous afternoon activities.

\section{Things that worked well}

As in the past conference, the format of the conference worked well. The modest number of oral presentations, all by invited speakers, permitted in-depth examination of the topics and illicited substantial discussions between the audience and speaker. The structure of the morning sessions and evening sessions with free afternoons encouraged several interactions among the participants. The choice of session topics was similar to prior years past, but included a new successful session of biotechnology chaired by Tom Baer.

On the second evening of the conference, the evening ended with a lighthearted panel discussion moderated and organized by Michael Feld. The comraderie established at the evening session set the atmosphere for the remainder of the meeting.

The poster session was extremely well attended, with almost 60 very high quality posters (both technical and illustration-wise). While the session was well attended, there was not sufficient time for most attendees to present their poster and view the other presenter's posters.

Owing to cancellations and logical constraints (see below), we rearranged the invited talk from Donald Coffey as the last talk of the meeting. Despite this normally unfavorable scheduling, Dr. Coffey's talk was fully attended and ended the conference on a very enthusiastic note. Dr. Coffey's full participation in the meeting was also a successful feature of the conference. 


\section{DISCLAIMER}

This report was prepared as an account of work sponsored by an agency of the United States Government. Neither the United States Government nor any agency thereof, nor any of their employees, makes any wartanty, express or implied, of assumes any legal liability or responsibility for the accuracy, completeness, or usefulness of any information, apparatus, product, or process disclosed, or represents that its use would not infringe privately owned rights. Reference herein to any specific commercial product, process, or service by trade name, trademark, manufacturer, or otherwise does not necessarily constitute or imply its endorsement, recommendation, or favoring by the United States Government or any agency thereof. The views and opinions of authors expressed herein do not necessarily state or refiect those of the United States Government or any agency thereof. 


\section{DISCLAIMER}

Portions of this document may be illegible in electronic image products. Images are produced from the best available original document. 
While the poster session was extremely well-attended, more time could have been allotted. The poster session should have been broken in two to give authors the chance to view one and others' posters. In addition, owing to logistic difficulties, poster prizes and platform presentations would have been a nice addition to the meeting.

Owing to the location of the conference, fundraising was more difficult (see NIH review). The perception at the Whitaker Foundation, NSF, and NIH was that the meeting was overpriced and in one SRA's description of its reception to the review board, a "junket" for the chair's friends and colleagues. Resubmission to the Whitaker Foundation was successful, but NIH submission was plagued by the review committee's decision not to discuss the conference merits at the panel. It is suggested that the next organizers contact Anne Menkins from NCI in the next funding round (for details, contact Sevick-Muraca at 409-845-3361). In addition, while FDA funding was highly likely, a lost submitted proposal at FDA and then once found, personnel problems between the FDA and the Engineering Foundation staff resulted in Dr. Sevick's mediating difficulties while away in Europe. In the end, much needed FDA funding was not received, owing to delays and less cooperative spirits at the Engineering Foundation to provide a Federal Express number to charge the mailing of a front page for an authorized signature. Industrial funding was also light. Nonetheless, funding was received to meet the registration and some travel costs of all graduate students and the invited speakers and organizers who requested financial assistance.

Owing to the lateness of the received funding, one entire session was cancelled from the meeting owing to lack of speakers and participants. Session chairs Rob Webb and Tom Deutsch cancelled owing to lack of funds to promise travel assistance. In addition, we had cancellations from speakers at very late stages that prevented replacement talks. Unfortunately, there was no OCT work highlighted in the invited list of presentations as a result of cancellations. Cancellations occurred from attendees and speakers without forewarning and raised conference costs as well as organizer anxiety. It is recommended that the attendees be reminded that cancellations be forwarded to the session chairs and conference organizers one week before the conference at the latest.

All in all, the cancellations did not negative impact the conference overall and the extra open time slot on Friday A.M. was used by groups to discuss research over a leisurely breakfast and engage in group activities. Again, the highlight of the meeting was building relationships, an objective that benefited in hindsight by the cancellation on one session. 


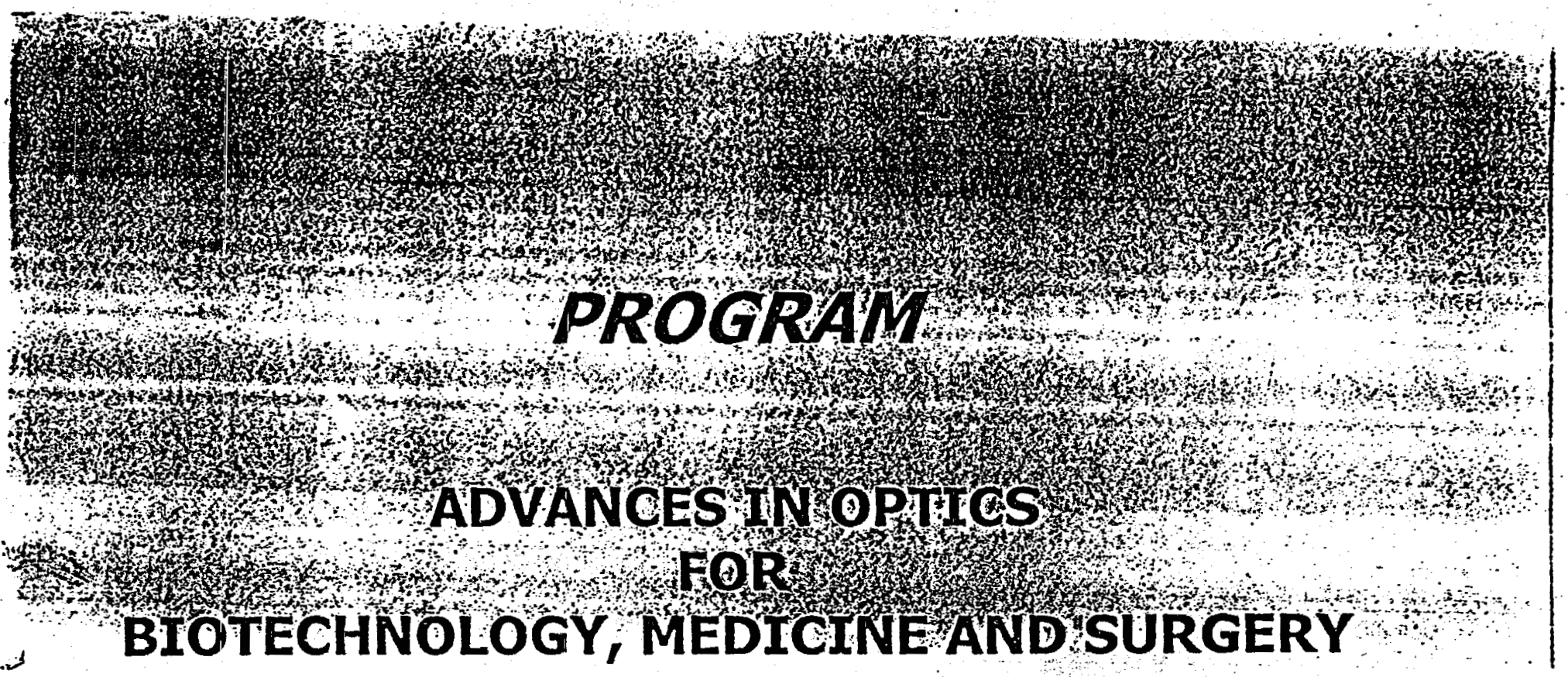

\author{
1- 6 August 1999 \\ Kona Surf Resort and Conference Center \\ 78-128 Ehukai Street \\ Kailua-Kona, Hawaii 96740 \\ Phone: 1-808-322-3411
}

Conference Co-Chairs:

Dr. David Benaron Stanford University
Dr. Eva M. Sevick-Muraca Purdue University

\author{
Dr. Arjun G. Yodh \\ University of Pennsylvania
}

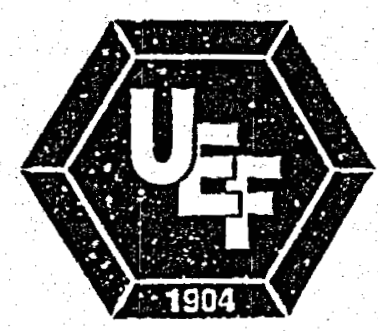

United Engineering Foundation, Inc.

Three Park Avenue; $27^{\text {th }}$ Floor

New York, NY 10016-5902

T: 1-212-591-7836 F: 1-212-591-7441

E-mail: engfnd@aol.com wwW:http://www.engfnd.org 


\section{Sunday, August 1, 1999}

4:00 p.m. - 6:00 p.m.

Registration (Conference Center Lanai)

6:00 p.m. - 7:30 p.m.

Dinner (Luau Gardens)

7:30 p.m. - 7:45 p.m.

Opening Remarks (Koa Room)

Dr. Eva Sevick-Muraca, Conference Chair

Dr. Charles Stott

United Engineering Foundation Technical Liaison

\section{SESSION I: PHOTODYNAMIC THERAPY: FUNDAMENTAL AND CLINICAL} STUDIES

Session Chair: Tayyaba Hasan, Wellman Laboratories

8:00 p.m. - 8:30 p.m.

8:30 p.m. - 9:00 p.m.

9:00 p.m. - 9:30 p.m.

9:30 p.m. - 10:00 p.m.

10:00 p.m. - 11:00 p.m.
An Overview of Photodynamic Therapy Mechanisms David Kessel, Wayne State University School of Medicine

Photodymanic Therapy for the Treatment of Age-Related Macular Degeneration

Andrew Strong, QLT PhotoTherapeutics, Inc.

Cardiovascular Applications of Photodynamic Therapy Kathryn Woodburn, Pharmacyclics

The Evolving Role of Photodynamic Therapy in Oncology John Hill, Miravant Medical Technologies

Social Hour (Koa Room) 
Monday, August 2, 1999

i

7:00 a.m. - 8:30 a.m. Breakfast (Nalu Terrace)

SESSION II: FRONTIERS IN SPECTROSCOPY (Koa Room)

Session Co-Chairs: Rebecca Richards-Kortum,

University of Texas at Austin

Michael Feld,

Massachusetts Institute of Technology

8:30 a.m. - 9:15 a.m.

Quantitative Biomarkers: Estimating Risk of Progression and Role in Cancer Chemoprevention Trials

Charles W. Boone, National Institute of Health

9:15 a.m. - 10:00 a.m. Blological Basis of Cervical Tissue Fluorescence and

Correlation with Blomarkers

Michelle. Follen, M.D. Anderson Cancer Center

10:00 a.m. - 10:30 a.m. Coffee Break (Lanai)

10:30 a.m. - 11:15 a.m. Biological Basis of Bronchlal Tissue Autofluorescence and Correlation with Blomarkers

Stephen Lam, British Columbia Cancer Agency

11:15 a.m. - 12:00 noon Statistical and Model Based Analysis of Spectral Data: Current Controversles and Future Opportunities

Joint Discussion:

Michael Feld, Massachusetts Institute of Technology and

Rebecca Richards-Kortum, The University of Texas at Austin

12:00 noon - 1:30 p.m. L Lunch (Nalu Terrace)

1:45 p.m. $-5: 45$ p.m. $\quad$ Ad hoc sessions and/or free time

5:45 p.m. - 7:15 p.m. Dinner (Luau Gardens)

SESSION III: FRONTIERS IN SPECTROSCOPY (Koa Room)

Session Co-Chairs: Michael Feld,

Massachusetts Institute of Technology

Rebecca Richards-Kortum,

The University of Texas at Austin

7:30 p.m.- 8:15 p.m. Near Infra-Red Transmission Spectroscopy for Blood Analyte Monitoring in Human Subjects

Mark A. Arnold, lowa Advances Technology Laboratories

University of lowa

8:15 p.m. - 9:00 p.m. Wavelength Dependent Feature Resolution In Digital

Colposcopy

Brian Pogue, Dartmouth College 
Monday, August 2, 1999 (Continued)

9:00 p.m. - 9:45 p.m. Diagnostic Spectroscopy in the Post-Microscopy Era: A Pathologist's Perspective Maryann Fitzmaurice, Case Western Reserve University \& University Hospitals

9:45 p.m. - 10:30 p.m. PANEL DISCUSSION (with Beer)

Fluorescence, Reflectance or Ratan: Which is the Winning Technique?

Fluorescence

Steve Jacques,

Reflectance

Irving Bigio, Los Alamos National Laboratory

Roman

Andrew Berger, University of California at Irvine

10:30 p.m. - 11:00 p.m. Beer Break Continues (Koa Room) 
Tuesday, August 3, 1999

7:00 a.m. - 8:30 a.m. Breakfast (Nalu Terrace)

SESSION IV: PHOTON MIGRATION (Koa Room)

Session Chair: Bruce Tromberg, Beckman Laser Institute,

University of California at Irvine

\begin{tabular}{|c|c|}
\hline 8:30 a.m. - 9:00 a.m. & $\begin{array}{l}\text { Continuous Bedside Monitoring and Imaging c } \\
\text { Oxygenation } \\
\text { David T. Delpy, Department of Medical Physics \& } \\
\text { University College London }\end{array}$ \\
\hline 9:00 a.m. - 9:30 a.m. & $\begin{array}{l}\text { Laser Mammography and Non-Invasive Optica } \\
\text { Cerebral Activity } \\
\text { Sergio Fantini, Department of Physics, University } \\
\text { Urbana-Champaign }\end{array}$ \\
\hline :30 a.m. - 10:00 a.m. & $\begin{array}{l}\text { Photon Migration Imaging and Spectroscopy } \\
\text { Michael S. Patterson, Hamilton Cancer Center }\end{array}$ \\
\hline 10:00 a.m. - 10:30 a.m. & Coffee Break (Lanai) \\
\hline 10:30 a.m. - 11:00 a.m. & $\begin{array}{l}\text { Optical Mammography } \\
\text { David Boas, Massachusetts General Hospital }\end{array}$ \\
\hline 11:00 a.m. - 12:00 noon & $\begin{array}{l}\text { Panel Discussion: } \\
\text { Britton Chance, University of Pennsylvania }\end{array}$ \\
\hline 2:00 noon - 1:30 p.m. & Lunch (Nalu Terrace) \\
\hline 1:45 p.m. - 5:30 p.m. & Ad hoc sessions and/or free time \\
\hline 00 p.m. - 7;30 p.m. & Dinner (Luau G \\
\hline
\end{tabular}

SESSION V: ADVANCES IN TISSUE MICROSCOPY, DYES AND REPORTERS (Koa Room)

Session Chair: Daniel Farkas, University of Pittsburgh and Carnegie Mellon University

8:00 p.m. $-8: 30$ p.m.

The Best Current in Vivo Microscopy: Live Confocal Microscopy

Milind Rajadhyaksha, Lucid, Inc.

8:30 p.m. - 9:00 p.m. Luciferase Reporter Gene

Christopher Contag, Stanford University

9:00 p.m. - 9:30 p.m. Labelling DNA for Sensitive Detection

Alan Waggoner, Fluorescent Dye Chemistry, Amersham

Pharmacia Biotech

9:30 p.m. - 10:30 p.m. Social Hour (Koa Room) 
Wednesday, August 4, 1999

7:00 a.m. - 8:30 a.m. Breakfast (Nalu Terrace)

SESSION VI: ADVANCES IN CELL MICROSCOPY: SPECTROSCOPY AND MICROMANIPULATION (Koa Room)

Session Chair: Daniel Farkas, University of Pittsburgh and

Carnegie Mellon University

8:30 a.m. - 9:00 a.m.

Single Molecule Imaging of Blomolecules at Work

Toshio Yanagida, Department of Physiology, Osaka University Medical School

9:00 a.m. - 9:30 a.m.

3-D Microscopy: Pushing the Limits of Speed and Resolution . Stefan Hell, High Resolution Optical Microscopy Group, Max

Planck Institute for Biophysical Chemistry

9:30 a.m. - 10:00 a.m. Coffee Break (Lanai)

10:00 a.m. - 10:30 a.m. New Methods inffor 3-D Microscopy

Tony Wilson, Department of Engineering Science, University of Oxford

10:30 a.m. - 11:00 a.m. Discussion

12:00 noon - 1:30 p.m. Lunch (Nalu Terrace)

1:30 p.m. - 5:45 p.m. Ad hoc sessions and/or free time

3:30 p.m. $-5: 30$ p.m. POSTER SESSION (Milo ROOm)

6:00 p.m. - 7:30 p.m. Dinner (Luau Gardens)

SESSION VII: LASER-TISSUE INTERACTIONS: THERAPEUTIC INTERVENTIONS (Koa Room)

.. Session Chair: Steven Jacques, Oregon Laser Center

8:00 p.m. - 8:30 p.m. Laser Thermal Shaping of Cartilage Implants

Brian Wong; Beckman Laser Institute, University of California

8:30 p.m. - 9:00 p.m. Laser Thrombolysis: Clearing Vessel Clots in Heart and Brain

Scott Prahl, Oregon Medical Laser Center

9:00 p.m. - 9:30 p.m. Photochemically Activated Adhesives for Tissues

Anastamosis

Mel Judy, Baylor Research Institute

9:30 p.m. - 10:30 p.m. Social Hour (Milo Room) 
Thursday, August 5, 1999

;

7:00.a.m. - 8:30 a.m. Breakfast (Nalu Terrace)

SESSION VIII: OPTICS FOR BIOTECHNOLOGY (KOa ROOM)

Session Co-Chairs: Tom Baer, Arcturus Engineering, Inc. and

Tom Deutsch, Wellman Laboratories,

Massachusetts General Hospital

8:30 a.m. - 9:00 a.m.

9:00 a.m. - 9:30 a.m.

9:30 a.m. - 10:00 a.m.

10:00 a.m. - 10:30 a.m.

10:30 a.m. - 11:00 a.m.

11:00 a.m. - 12:00 noon

12:00 noon - 1:30 p.m.

1:45 p.m. - 6:30 p.m.

7:00 p.m. - 10:00 p.m.
Simultaneous 10 Channel Fluorescence Tagging and Flow Cyometric Analysis of Leukocytes: Applications to Immune System Monitoring and HIV

Mario Roederer, Stanford University

Gene Expression Analysis Using Laser Capture

Microdissection and Fluorescent cDNA Microarrays

Mark Erlander, R.W. Johnson Pharmaceutical Institute

Coffee Break (Lanai)

Optics in Medicine

Frank Hillenkamp, Universităt Mänster

The Future of MS, PET, and Optical Imaging

Robert Lenkinski, University of Pennsylvania

Coffer

Discussion

Lunch (Nalu Terrace)

LUNCHEON SPEAKER

D.S. Coffey, Johns Hopkins

Molecular Blology of Cancer

Ad hoc sessions and/or free time

Luau (Luau Gardens)

Awards 
Friday, August 6, 1999

7:00 a.m. - 8:30 a.m.

Breakfast (Nalu Terrace)

SESSION IX:

9:00 a.m. - 10:00 a.m. Meeting Summary by session chairs and session organizers

10:00 a.m.

Boxed lunches ready for all participants 


\section{POSTERS}

1. Comparison of PDT Efficiencies for Photooxidation of Substrate (NADPH) and Photobleaching of Photosensitizer (Photofrin II)

Paulo R. Bargo and Steven L. Jacques

Oregon Graduate Institute of Science and Technology, Oregon Medical Laser Center, USA

Parmeswaran Diagaradjane

Division of Medical Physics \& Lasers, Department of Physics, Anna University, INDIA

2. High Speed, High Resolution, Phase Resolved Optical Doppler Tomography

Yonghua Zhao, Zhongping Chen, Christopher Saxer, Johannes de Boer and

J. Stuart Nelson

Beckman Laser Institute of Medical Clinic, University of California-Irvine, USA

3. Finite-Difference Modeling of Thermal Camera Temperature Measurements During

Laser Irradiation

Bernard Choi, John A. Pearce, and Ashley J. Welch

Biomedical Engineering Laser Laboratory. The University of Texas at Austin, USA

4. Optical Coherence Tomography in Dentistry

Bill Colston, Ujwal Sathyam, and Matthew Everett

Lawrence Livermore National Laboratory, USA

Linda Otis

University of Connecticut Health Center, USA

5. Diagnosis and Treatment of Breast Tumours Through the Combined Use of Optical

Biopsy and Interstitial Laser Photocoagulation

Paul M. Ripley

Department of Medical Physics, University College of London, UNITED KINGDOM

G. Briggs and S.G. Brown

National Medical Laser Centre, University College of London, UNITED KINGDOM

J.R. Mourant and I.J. Bigio

Los Alamos National Laboratory, USA

6. A Computational Study of Laser Treatment of Port Wine Stains With Cryogen Spray

Cooling

T. Joshua Pfefer, Thomas E. Milner and A.J. Welch

Biomedical Engineering Program, The University of Texas at Austin, USA

Derek J. Smithies and J. Stuart Nelson

Beckman Laser Institute and Medical Clinic, University of Califomia-Irvine, USA

7. Light Scattering From Cervical Cells: Modeling, Measurements, and Methods to

Enhance Nuclear Scattering

Rebekah Drezek, Andres Zuluaga, Tom Collier and Rebecca Richards-Kortum

University of Texas at Austin, USA

Calum MacAulay

British Columbia Cancer Center, CANADA 
Posters 99-AN

Page Two

8. Simultaneous Fluorescence and Sub-Surface Structural Measurements: MultiFunctional Optical Probing With Spatially Resolved Spectral Interferometry (SRSI) Andres F. Zuluaga, and Rebecca Richards-Kortum

The University of Texas at Austin, USA

Calum MacAulay

Bristish Columbia Cancer Agency, CANADA

9. ND-YAG and $\mathrm{CO}_{2}$ Laser Irradiation of Apex in Endodontic Microsurgery

Sebastiano Tosto

ENEA Casaccia, Innovation Department, ITALY

Noberto Berna and Marco Melis

Roma University, ITALY

10. Photo-Thermal Profiling of Vascular Lesions Utilizing Two Excitation Wavelengths Boris Majaron, Wim Verkruysse and J. Stuart Nelson

Beckman Laser Institute of Medical Clinic, University of California at Irvine, USA

Tom Milner

Biomedical Engineering Program, University of Texas, USA

Sam Tanenbaum

Department of Engineering, Harvey Mudd College, USA

11. Imaging at Multiple Frequencies Using Amplitude Only: A Surprisingly Beneficial Approach

Vasilis Ntziachristos, A.G. Yodh and Britton Chance

University of Pensylvania, USA

12. Caries Detection Using Polarization-Sensitive Optical Coherence Tomography

Ujwal S. Sathyam, Matthew J. Everett, Bill W. Colston, Jr., and Luiz B. Da Silva

Lawrence Livermore National Laboratory, USA

13. Quantifying the Importance of High Angle Scattering Events to Light-Transport

Throught Turbid Media Measured in a Backscattering Geometry

Murat Canpolat and Judith R. Mourant

Chemical Sciences and Technology Division, Los Alamos National Laboratory, USA

14. Diagnosis of Ocular Surface Neoplasia by Optical Spectral Analysis

Steven Chalfin, and Randolph D. Glickman

Department of Ophthalmology, University of Texas Health Science Center, USA

15. Spatial Discrimination of Optically Induced Acoustic Sources In Tissue Phantoms Using Matched Field Processing

John A. Viator, Steve L. Jacques and Scott A. Prahl

Oregon Medical Laser Center, USA

16. Chemometric Extraction of Optical Properties and Chromophore Concentrations

From Frequency Domain Photon Migration Data

Andrew J. Berger, Vasan Venugopalan, Anthony J. Durkin, Tuan H. Pham, and

Bruce Tromberg

Beckman Laser Institute and Medical Clinic, USA 
Posters 99-AN

Page Three

17. Opto-Acoustic Monitoring of Blood Glucose

Alexander A. Oraevsky, Andrey Bednov, Kirill Larin and Alexander Karabutov University of Texas Medical Branch, USA

18. Burn Diagnosis by Diffuse Photon-Density Wave Reflectance Measurements Thorsten Spott* and Lars O. Svaasand

Norwegian University of Science and Technology, NORWAY

*Currently at Beckman Laser Institute and Medical Clinic, USA

Tuan Pham and Bruce J. Tromberg

Beckman Laser Institute and Medical Clinic, USA

19. Opto-Acoustic Cell Permeation

Steven R. Visuri

Lawrence Livermore National Laboratory, USA

20. Polarization Spectroscopy of Cervical Epithelium for Pre-Cancer Detection Konstantin Sokolov, Kirk Gossage, Rebekah Drezek and Rebecca Richards-Kortum Biomedical Engineering. The University of Texas at Austin, USA

21. Polarized Light Propagation Through Tissue and Tissue Phantoms Vanitha Sankaran and Duncan J. Maitland Lawrence Livermore National Laboratory, USA Joseph T. Walsh, Jr., Northwestern University, USA

22. Two-Photon Fluorescence Microscopy in Turbid Media Andrew Dunn, Vincent Wallace, Mariah Coleno and Bruce Tromberg Beckman Laser Institute, University of California-Irvine, USA

23. Microstructure Imaging of in Vivo Human Skin Tissue By Optical Coherence Tomography

S.H. Xiang, Y. Zhao, S. Chen and J.S. Nelson

Beckman Laser Institute and Medical Clinic, University of California at Irvine, USA

24. Monte Carlo Modeling of Polarized LIght Propagation In Multiple Scattering Media Sebastian Bartel and A.H. Hielscher

State University of New York, USA

25. In Vivo Reflectance Spectroscopy of Ovarian Tissue

Urs Utzinger, and Rebecca Richards-Kortum

Biomedical Engineering Program, The University of Texas at Austin, USA

Molly Brewer

Department of Gynecology, The University of Texas Medical School, USA

26. Near IR Diffuse Light Studies of Blood Flow and Hemoglobin Saturation in Mice

Tumors During Photodynamic Therapy

Joseph P. Culver, Cecil Cheung and Arjun Yodh

Department of Physics \& Astronomy, University of Pennsylvania, USA

Cindy Skema and Joseph Freidberg

Department of Surgery, University of Pennsylvania, USA 
Posters 99-AN

Page Four

27. Bridging the Gap Between Photon Migration Imaging and Fluorescence Microscopy

Britton Chance and S. Zhou

University of Pennsylvania, USA

K. Kang

University of Maryland, USA

28. Spectral Variation of Infrared Absorption Coefficient in Pulsed Photothermal Profiling of Biological Tissue

Wim Verkruysse, Boris Majaron and J. Stuart Nelson

Beckman Laser Institute and Medical Clinic, USA

B. Samuel Tanenbaum

Harvey Mudd College, USA

Thomas E. Milner

University of Texas at Austin, USA

29. The Combination of Fluorescence and Reflectance Spectroscoples as a Tool for the Detection of Premalignacies in the Esophagus and the Stomach

Irene Georgakoudi, Qingguo Zhang, Markus G. Mäeller and Michael S. Feld

Massachusetts Institute of Technology, G.R. Harrison Spectroscopy Laboratory, USA

Brian C. Jacobson, Jonathan Glickman and Jacques Van Dam

Brigham and Women's Hospital, USA

30. Quantification of Fetal Cerebral Blood Oxygenation in Utero by Frequency Domain NIR Spectroscopy: Semi-Infinite \& Two-Layer Approximation

Regine Choe and A.G. Yodh

Department of Physics \& Astronomy, University of Pennsylvania, USA

Gargi Vishnoi, Nirmala Ramanujam and Britton Chance

Department of Biochemistry and Biophysics, University of Pennsylvania, USA

31. Clinical Characterization of Colonic Mucosal Lesions in Vivo Using Autofluorescence and Delta-Aminolevulinic Acid Sensitization

Charlotta Eker, Stefan Andersson-Engels and Katarina Svanberg

Lund University Medical Laser Centre, Department of Physics, Lund Institute of Technology,

SWEDEN

Edgar Jaramillo and Eduard Jonas

Division of Internal Medicine, Karolinska Hospital, SWEDEN

32. Multi-Wavelength Determination of Fat Optical Properties Using Frequency Domain

Photon Migration

Charlotta Eker

Lund University Medical Centre, Department of Physics, Lund Institute of Technology,

SWEDEN

Natasha Shah, Tuan Pham and Bruce Tromberg

Beckman Laser Institute and Medical Clinic, University of California at Irvine, USA 
Posters 99-AN

Page Five

33. Depth-Resoveld Birefringence Imaging in the Eye With Polarization-Sensitive Optical Coherence Tomography

Mathieu G. Ducros, H. Grady Rylander and Thomas E. Milner

Biomedical Engineering Program, University of Texas at Austin, USA

Johannes F. de Boer and Huai-En Huang

Beckman Laser Institute and Medical Clinic, USA

34. Algorithms for 3D Localization and Imaging Using Near-Field Diffraction Tomography with Diffuse Light

Turgut Durduran, J.P. Culver, M.J. Holboke, X.D. Li , Leonid Zubkov, Deva N. Pattanayak and A.G. Yodh

Department of Physics and Astronomy, University of Pennsylvania, USA

B. Chance

Department of Biophysics and Biochemistry, University of Pennsylvania, USA

35. Detector and Calibration Studies for UV Laser Induced Fluorescence Detection of Trace Chemical Concentrations in Aqueous Solutions

Dennis K. Killinger and Vasanthi Sivaprakasam

Department of Physics, University of South Florida, USA

36. Compact Medical Fluosensor for Minimally Invas/ve Tissue Characterisation Stefan Andersson-Engels, Claes af Klinteberg, Markus Andreasson, Ola Sandström and Sune Svanberg

Department of Physics, Lund Institute of Technology, Sweden

37. NIR Spectroscoplc Studies of Fetal Brain In-Utero: Evaluation of Sensitivity and Accuracy of the System to the Fetal Cerebral Blood Saturation

Gargi Vishnoi, Nirmala Ramanujam, Shoko Nioka and Britton Chance

School of Medicine, University of Pennsylvania, USA

Andreas H. Hielscher

Department of Pathology, State University of New York, USA

38. Polarized Llght Scattering Spectroscopy for Diagnosis of Precancer

Rajan S. Guriar

George R. Harrison Spectroscopy Laboratory, Massachusetts Institute of Technology, USA

L.T. Perelman, Vadim Backman, Iving Itzkan, R.R. Dasari and M.S. Feld

Massachusetts Institute of Technology, USA

Kamran Badizadegan

Children's Hospital, USA

39. Dynamic Tomographic Imaging of Vascular Reperfusion

Christoph H. Schmitz, Harry L. Graber, Andreas H. Hielscher and Randall L. Barbour

SUNY Health Science Center at Brooklyn, USA

40. Polarized, Wavelength Dependent Elastic-Scatter Spectra

Judith R. Mourant and Tamara M. Johnson

Los Alamos National Laboratory, USA 
Posters 99-AN

Page Six

41. Two-Photon Excited Imaging of Tissue Remodeling

Vincent P. Wallace, Mariah L. Coleno, Chung-Ho Sun and Bruce J. Tromberg

Beckman Laser Institute, University of California at Irvine, USA

42. Monte Carlo Simulations of Polarized Light Propagation In Microsphere Suspensions Duncan Maitland, Vanitha Sankaran, George Zimmerman and Richard London

Lawrence Livermore National Laboratory, USA

43. Measurements of the Optical Trap Stiffness: Two-Photon Fluorescence to the Rescuel

Tatiana B. Krasieva, Ph.D., Andrew K. Dunn, Ph.D., Joon S. You and Bruce J. Tromberg, Ph.D.

Beckman Laser Institute, University of California at Irvine, USA

44. MIT Laser Biomedical Research Center.

Lev T. Perelman, Qingguo Zhang, Irving Itzkan, Ramachandra R. Dasäri and Michael S.

Feld

Massachusetts Institute of Technology, USA

45. Functional Cerebral Activity Measurement by Diffusing Light

Cecil Cheung and A.G. Yodh

Department of Physics and Astronomy, University of Pennsylvania, USA

K. Takahashi and J.H. Greenberg

Cerebrovascular Research Center, Department of Neurology, University of Pennsylvania,

School of Medicine, USA

46. Spectral Analysis of Two Photon Excited Fret of GFP Fusion Proteins

Vickie J. LaMorte, Ph.D., Andrew Dunn, Ph.D., Mariah L Coleno, Vincent Wallace, Ph.D., Tatiana B. Krasieva, Ph.D., Gopy K. Manthripragada and Bruce J. Tromberg, Ph.D.

Beckman Laser Institute, University of California at Irvine, USA

47. Near-Infrared Spectroscopy to Diagnose Alzheimer's Disease

Eugene B. Hanlon, Irving Itzkan, Ramachandra R. Dasari and Michael S. Feld

Massachusetts Institute of Technology, USA

Neil W. Kowall

Boston University School of Medicine, USA

48. Near-Infrared Tomographic Imaging of Breast Lesions in Vivo

Brian W. Pogue, Troy O. McBride, Ulf L. Osterberg and Keith D. Paulsen

Thayer School of Engineering, Dartmouth College, USA

Steven P. Poplack

Department of Radiology, Dartmouth-Hitchcock Medical Center, USA

49. Endovascular Photodynamic Therapy to Prevent Intimal Hyperplasia After Vascular Interventions

E.E.E. Gabeler MD, R. van Hillegersberg Ph.D. MD, W. Sluiter Ph.D., R.G. van Eps MD and H. van Urk Ph.D. MD 
Posters 99-AN

Page Seven

50. Electromagnetic Modeling of LIght Propagation Through Blological Tissue: Applications to Reflectance Spectroscopy and Optical Coherence Tomography Rebekah Drezek, Andres Zuluaga, Andrew Dunn and Rebecca Richards-Kortum University of Texas at Austin 


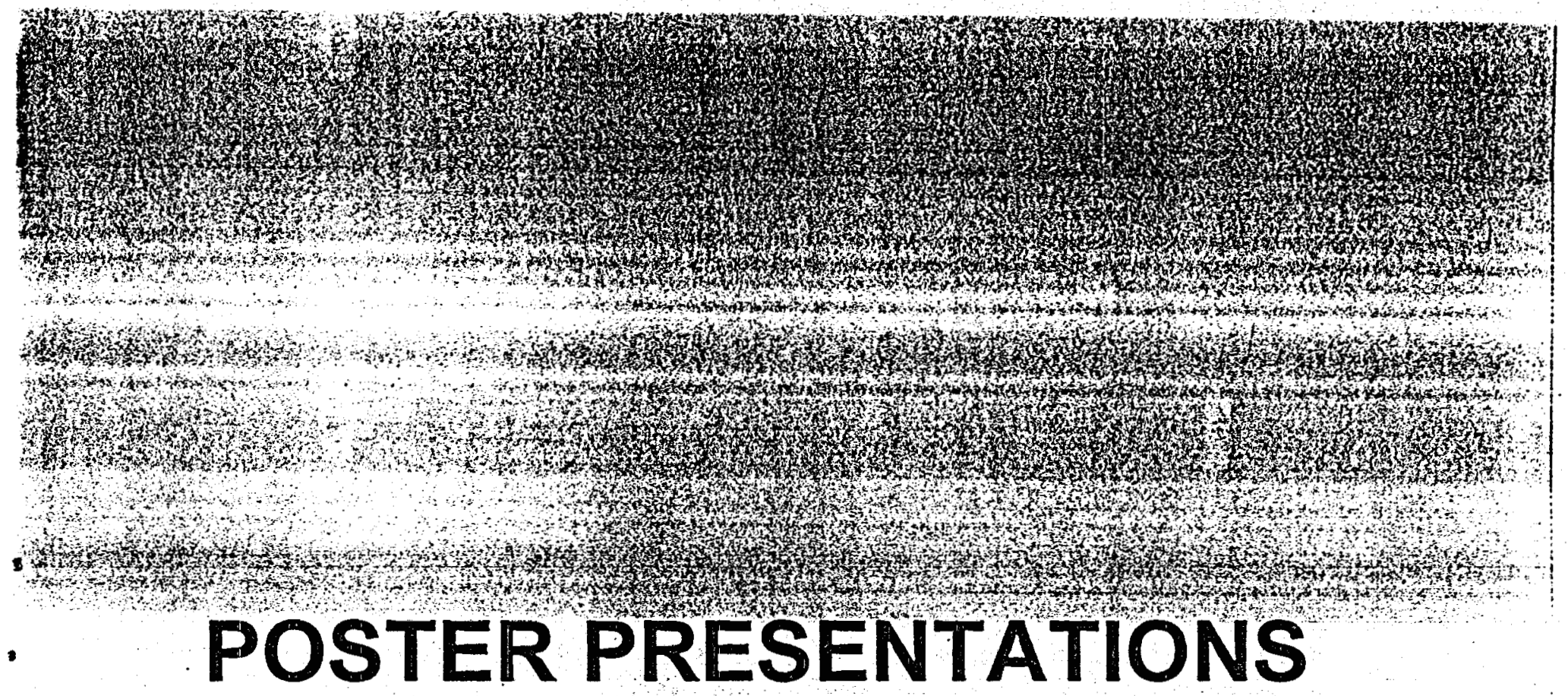


Comparison of PDT efficiencies for photooxidation of substrate (NADPE) and photobleaching of photosensitizer (Photofrin II).

Paulo R. Bargo', Parmeswaran Diagaradjane ${ }^{2}$ and Steven L. Jacques ${ }^{1}$

1 Oregon Medical Laser Center (http://omlc.ogi.edu); Oregon Graduate Institute of Science and Technology (pbargo@ece.ogi.edu sjacques@ece.ogi.edu)

2 Division of Medical Physics \& Lasers, Department of Physics, Anna University, Chennai 600 025. INDIA (d_parmesh@hotmail.com)

INTRODUCTION: We studied photooxidation and photobleaching during PDT (photodynamic therapy) in a model system using NADPH as the target substrate and Photofrin $I$ as the photosensitizer. The efficiency of NADPH oxidation per photon absorbed by photosensitizer was determined as a function of substrate concentration. The efficiency of photosensitizer photobleaching and the spectral changes were measured. The influences of sodium azide, a singlet oxygen scavenger, and albumin on these efficiencies were determined. METHODS: NADPH (1-10 mM) was mixed with TRIZMA buffer (50 mM), Photofrin ( 50 $\mathrm{ug} / \mathrm{ml}), \pm$ human albumin ( $1 \mathrm{mg} / \mathrm{ml})$, and \pm sodium azide $(1-5 \mathrm{mM})$. Each test solution was irradiated with an argon laser $(488 \mathrm{~nm})$ for different exposure times $(0-90 \mathrm{~min})$. The kinetics of changes in absorbance $(340 \mathrm{~nm})$ and fluorescence $(540-800 \mathrm{~nm})$ were measured to assay oxidation of NADPH and photobleaching of Photofrin. RESULTS: The efficiency of oxidation increased $(0.035: 0.087: 0.308)$ with increasing NADPH concentration $(1: 3.5: 10 \mathrm{mM})$, consistent with the tentative relation:

$$
\text { Efficiency of oxidation }=0.42 \cdot(1-\exp (-\mathrm{C} / 9.5 \mathrm{mM}))
$$

where $C$ is the NADPH concentration [mM] and 0.42 is consistent with the literature. The $9.5 \mathrm{mM}$ value is related to the diffusuvity and lifetime of the singlet oxygen. Albumin did not affect the efficiencies of oxidation or photobleaching, although a 14-fold increase in the fluorescence was observed. Azide ( $5 \mathrm{mM}$ ) reduced the efficiency of $1 \mathrm{mM}$ NADPH oxidation 8-fold but had little effect on photobleaching of Photofrin II. The ability of photobleaching to predict the amount of photooxidation was not immediately obvious but there were specific spectral changes that may prove useful.

Paulo Bargo

Oregon Medical Laser Center

St. Vincent Hospital

9205 SW Bames Rd.

Portland, OR 97225

503-216-6830 phone

503-216-2422 FAX

pbargo@ece.ogi.edu

supervisor: Steven L. Jacques

503-216-4092 phone

sjacques@ece.ogi.edu 


\section{ADVANCES IN OPTICS \\ FOR BIOTECHNOLOGY, MEDICINE AND SURGERY}

\section{HIGH SPEED, HIGH RESOLUTION, PHASE RESOLVED OPTICAL DOPPLER TOMOGRAPHY}

Yonghua Zhao, Beckman Laser Institute and Medical Clinic, University of California, Irvine 1002 Health Science Rd., Irvine, CA, 92612, U.S.

T: 949-824-3284,F: 949-824-8413, yzhao@bli.uci.edu, or zchen@bli.uci.edu Zhongping Chen, Beckman Laser Institute and Medical Clinic, University of California, Irvine Christopher Saxer, Beckman Laser Institute and Medical Clinic, University of California, Irvine Johannes de Boer, Beckman Laser Institute and Medical Clinic, University of California, Irvine J. Stuart Nelson, Beckman Laser Institute and Medical Clinic, University of California, Irvine

Optical Doppler Tomography (ODT) is a recently developed imaging modality that combines laser Doppler flowmetry with optical coherence tomography to obtain high resolution tomographic images of static and moving constituents in highly scattering biological tissues. However, ODT images are currently being processed by calculating the centroid of the power spectrum of the interference fringe using a short-time Fourier transformation (STFT). Inasmuch as detection of the Doppler shift requires sampling the interference fringe intensity over at least one oscillation cycle, acquisition time is limited by the STFT window size. We present here a phase resolved ODT system with high spatial resolution and real-time scanning rates. The system is based on a fiber integrated Michelson interferometer using a rapid-scanning optical delay line with an Electro-optic modulator. To obtain the Doppler frequency shift in a very short time, which is necessary to maintain high spatial resolution, two new image reconstruction approaches were developed for our system. One uses a Hilbert transformation to obtain the phase information at each sample point from the recorded interferometer fringe. The Doppler frequency shift is then derived from the phase velocity between two sample points. The other approach uses optical polarization to generate two quadrant signals: one corresponds to the real part of the complex signal and the other corresponds to the imaginary part. The advantage of the latter method is that no complex transformation is needed and real-time imaging can be implemented. Both computed simulation and experimental results from phase resolved ODT would be discussed. 
ADVANCES IN OPTICS

FOR BIOTECHNOLOGY, MEDICINE AND SURGERY

\title{
FINITE-DIFFERENCE MODELING OF THERMAL CAMERA TEMPERATURE MEASUREMENTS DURING LASER IRRADIATION
}

\author{
Bernard Choi, The University of Texas at Austin \\ Biomedical Engineering Laser Laboratory; ENS Building, Room 610, Austin, TX, 78712-1084, \\ USA \\ T: 512-471-9497, F: 512-475-8854, berniec@mail.utexas.edu \\ John A. Pearce, The University of Texas at Austin \\ Ashley J. Welch, The University of Texas at Austin
}

The use of thermographic techniques has increased as thermal camera technology has evolved and improved. For laser-tissue interactions, thermal cameras have been used to monitor the thermal response of tissue to pulsed and continuous wave irradiation.

It is important to note that the temperature measured with the thermal camera may not be equal to the actual surface temperature. An analysis by Pearce et al. [1] concluded that the actual surface emissive power [W/cm $]$ may be underestimated by factors as high as 13.6 . It is crucial to understand the limitations of using thermal cameras to measure temperature during laser irradiation of tissue. This study, based upon the initial work of Pearce et al., uses a simple 1-D finite-difference model to demonstrate potential discrepancies between the actual and measured surface temperatures.

The goal of this research is to provide an idea of 1 ) the underestimation in surface temperature measured with the thermal camera as a function of time and 2) the time required for the actual and measured surface temperatures to be approximately equal. Various ablation models from the literature [2-4] have been incorporated to add more realism to the temperature-time histoty predicted by the model. We are in the process of implementing surface cooling, and subsurface temperature peaks in general, into the computer simulation.

\section{REFERENCES}

1. Pearce JA, Welch AJ, Motamedi M, and Agah R. Thermographic measurement of tissue temperature during laser angioplasty. In: Diller KR, Roember RB, eds. Heat and Mass Transfer in the Microcirculation of Thermally Significant Vessels. 1986:49-54.

2. Partovi F, Izatt JA, Cothren RM, Kittrell C, Thomas JE, Strikwerda S, Kramer JR, and Feld MS. A model for thermal ablation of biological tissue using laser radiation. Lasers Surg Med 1987; 7:141-154.

3. Sagi A, Shitzer A, Avidor A, Akselrod S, and Katzir A. Heating and cutting of biological tissue by highly absorbed laser beams: Theoretical model and experiments. Proceedings SPIE 1990; 1202:228-233.

4. Jacques SL. Finite-difference modeling of laser ablation of tissue. Proceedings SPIE 1993; $1882: 422-431$. 


\title{
ADVANCES IN OPTICS \\ FOR BIOTECHNOLOGY, MEDICINE AND SURGERY \\ OPTICAL COHERENCE TOMOGRAPHY IN DENTISTRY
}

\author{
Bill Colston, Lawrence Livermore National Laboratory \\ 7000 East Avenue, Livermore, California, 94550, USA \\ T: 925-423-0375, F: 925-424-2778, colston1@llni.gov \\ Ujwal Sathyam, Lawrence Livermore National Laboratory \\ Matthew Everett, Lawrence Livermore National Laboratory \\ Linda Otis, University of Connecticut Health Center
}

We have, previously, provided evidence that optical coherence tomography (OCT) is useful for a wide variety of dental applications, including diagnosis of soft tissue diseases, detection of caries, and evaluation/monitoring of tooth restorations. Despite the promise of these early studies, however, at least two series of events must occur for this technology to become a widely available diagnostic in dental clinics. First, clinical evaluations must be performed correlating OCT imaging and currently accepted diagnostic markers of disease state. Secondly, the cost and complexity of dental OCT systems must be reduced to the level of current radiographic devices. This talk will address the current progress made by our group in these areas, focusing on results from recent small scale clinical trials. In addition, we will outline the technical hurdles that we have had to overcome during our development of a modular, inexpensive dental OCT imaging system, including such issues as intraoral handpiece design, identification/elimination of image artifacts, and image registration/processing. Finally, we will provide likely directions for future development work in the area of dental OCT. 


\title{
ADVANCES IN OPTICS \\ FOR BIOTECHNOLOGY, MEDICINE AND SURGERY
}

\section{DIAGNOSIS AND TREATMENT OF BREAST TUMOURS THROUGH THE COMBINED USE OF OPTICAL BIOPSY AND INTERSTITIAL LASER PHOTOCOAGULATION}

\author{
Paul M Ripley, Dept. Medical Physics, University College London \\ Ist Floor Shropshire House, 11-20 Capper Street, London, WC1E 6JA, UK \\ T: 44-171-209-6440, F: 44-171-209-6269, pripley@medphys.ucl.ac.uk \\ G. Briggs, National Medical Laser Centre, UCL, London, UK. \\ J R Mourant, Los Alamos National Laboratory, NM, US \\ I J Bigio, Los Alamos National Laboratory, NM, US \\ S G Bown, National Medical Laser Centre, UCL, London, UK.
}

Objective: To establish the feasibility of using two new technologies, ("optical biopsy" based on Elastic-Scattering Spectroscopy (ESS) and Interstitial Laser Photocoagulation (IILP)), for the instant diagnosis and treatment of breast tumours. It is envisaged that the combination of these techniques could provide a novel, minimal-access procedure that can be performed through the same needle. This has the potential to reduce the trauma of waiting for test results, along with offering a treatment that has cosmetic appeal.

Materials and Methods: Two independent studies have been undertaken in parallel. Normal and abnormal (benign and malignant), ex-vivo breast tissue samples taken from 15 patients were tested with the ESS system and the results correlated with conventional histology. In addition, 14 patients with benign palpable lesions, (histologically-proven fibroadenomas, diameter $<3.5 \mathrm{~cm}$ ), were treated with ILP and followed with serial ultrasound (US) at 3, 6, and 12 months.

Results: The preliminary ESS findings suggest distinct spectral features associated with benign and malignant disease compared with normal breast tissues. From the ILP study, none of the 14 patients had a palpable lesion at 12 months. Only 1 patient still had a detectable lesion $(9 \mathrm{~mm})$ on US imaging. Conclusions: Algorithms for analysing the ESS spectra require a much larger data-base, but these preliminary results suggest considerable potential for this technique, and new studies are invoking invivo measurements of ESS. The ILP results on fibroadenomas show that necrosed tissue in the breast can be resorbed safely. This argues well for the future treatment of cancers. 


\title{
ADVANCES IN OPTICS \\ FOR BIOTECHNOLOGY, MEDICINE AND SURGERY
}

\section{A COMPUTATIONAL STUDY OF LASER TREATMENT OF PORT WINE STAINS WITH CRYOGEN SPRAY COOLING}

\author{
T. Joshua Pfefer, The University of Texas at Austin \\ Biomedical Engineering Program, ENS 610, Austin, Texas, 78712, USA \\ T: (512)471-4703, F: (512)475-8854, pfefer@ccwf.cc.utexas.edu
}

Thomas E. Milner, Biomedical Engineering Program, The University of Texas at Austin

A: J. Welch, Biomedical Engineering Program, The University of Texas at Austin

Derek J. Smithies, Beckman Laser Institute and Medical Clinic, University of California, Irvine

J. Stuart Nelson, Beckman Laser Institute and Medical Clinic, University of California, Irvine

Thermal injury to the epidermis and dermis during laser treatment of cutaneous vascular lesions such as Port Wine Stains (PWS) is a significant problem, particularly for long pulse durations. One method which has been shown to be effective in reducing superficial cutaneous thermal injury is cryogen spray cooling. In this study, a novel computational model which has the ability to simulate light propagation, heat transfer, and thermal damage in biological tissues with realistic structure was used to simulate laser treatment of PWS in combination with cryogen cooling.

A three-dimensional, high-resolution tomographic reconstruction of a PWS biopsy was implemented in the model. Simulations were performed to investigate pulsed cryogen cooling (with pre-laser onset cooling durations, of 0,20 , and $50 \mathrm{~ms}$ ) used in combination with laser irradiation (tp $=5,10 \mathrm{~ms} ; 1=$ $585 \mathrm{~nm}$ ). The effect of parameter variations and tissue morphology on temperature rise and spatial extent of coagulation were investigated.

Modeling results indicated that treatment involving simultaneous onset of irradiation and cooling may prevent coagulation throughout the epidermis for $t p=5 \mathrm{~ms}$, and to within a few microns of the dermal/epidermal junction for $t p=10 \mathrm{~ms}$. Longer pre-cooling durations reduced coagulation in perivascular regions to a depth of $200 \mathrm{~mm}$. The thickness of perivascular damage was dependent on local vascular morphology as well as pre-cooling and laser pulse durations. Optimal treatment parameters of tp $=5 \mathrm{~ms}$ and a $50 \mathrm{~ms}$ pre-cooling duration were predicted for the reconstructed PWS anatomy.

This novel modeling approach has significant potential as a tool for planning patient-specific PWS treatment protocols, as well as for investigating a variety of diagnostic and therapeutic applications. Future studies are discussed, including the implementation of realistic tissue morphology and phase functions in simulations of reflectance and fluorescence spectroscopy with the goal of improving optical detection of cervical dysplasia. 


\title{
ADVANCES IN OPTICS \\ FOR BIOTECHNOLOGY, MEDICINE AND SURGERY
}

\section{LIGHT SCATTERING FROM CERVICAL CELLS: MODELING, MEASUREMENTS, AND METHODS TO ENHANCE NUCLEAR SCATTERING}

\author{
Rebekah Drezek, University of Texas at Austin \\ Engineering Science Building, Rm 610, Austin, TX, 78712, USA \\ T: (512) 471-3619, F: (512) 475-8854, drezek@ece.utexas.edu \\ Andres Zuluaga, University of Texas at Austin \\ Tom Collier, University of Texas at Austin \\ Calum MacAulay, British Columbia Cancer Center \\ Rebecca Richards-Kortum, University of Texas at Austin
}

Confocal microscopy and optical coherence tomography (OCT) are proposed optical technologies for detecting pre-cancerous conditions in tissue. Both methods assess tissue pathology based on changes in scattering which result from microscopic variations in morphology and biochemistry. To advance the development of clinical applications for these methods, we studied sub-cellular sources of scattering in normal and neoplastic cells and how contrast agents can modulate scattering, facilitating accurate optical diagnosis.

A three-dimensional finite-difference-time-domain method, which computes phase functions for cells of spatially varying refractive index, was developed and used to simulate scattering from cells from each stage of cervical intraepithelial neoplasia (CIN), including cells from progressive and regressive lesions. Nuclear morphology was measured using a Cyto-Savant device and used as model input. Scattering cross-sections increased with CIN progression due to elevated nuclear-to-cytoplasm (N/C) ratios and increased DNA content. To provide a comparison to model predictions, a goniometer was constructed and used to measure the phase functions of cervical cells.

Contrast agents can alter cell scattering properties, potentially enhancing the clinical utility of optical techniques. Confocal microscopy and OCT images of cells, fresh tissue sections, and biopsies from normal and dysplastic cervix were measured before and after application of contrast agents. The confocal imaging system resolved sub-cellular detail throughout the entire epithelial thickness. Normal and dysplastic tissue were clearly differentiable, and N/Cs ratios appeared to correlate well with histology. Increased nuclear scattering after addition of acetic acid aided visual discrimination between normal and dysplastic tissue imaged with the confocal microscope. Goniometric and scattering cross section measurements confirmed increased scattering after acetic acid application. Toluidine blue, another potential contrast agent, also intensified scattering from cell nuclei during confocal imaging. The contrast agents improved OCT image quality as well, heightening contrast between cellular and stromal layers. 


\title{
ADVANCES IN OPTICS \\ FOR BIOTECHNOLOGY, MEDICINE AND SURGERY
}

\section{SIMULTANEOUS FLUORESCENCE AND SUB-SURFACE STRUCTURAL MEASUREMENTS: MULTI-FUNCTIONAL OPTICAL PROBING WITH SPATIALLY RESOLVED SPECTRAL INTERFEROMETRY (SRSI)}

\author{
Andres F. Zuluaga, The University of Texas at Austin \\ ENS 610, 24th and Speedway Streets, Austin, TX, 78712, USA \\ T: (512) 471-1197, F: (512) 475-8854, a.f.zuluaga@mail.utexas.edu \\ Calum MacAulay, British Columbia Cancer Agency \\ Rebecca Richards-Kortum, The University of Texas at Austin
}

Optical, spectral domain, interferometric techniques $[1,2]$ for the determination of sub-surface structure have been investigated as an alternative to optical coherence tomography to probe microscopic structure in biological media. Recently we presented a modification of these techniques for the acquisition of a 2-dimensional (surface and depth) image [3]. Here we present a proof of concept implementation of spatially resolved spectral interferometry (SRSI) which allows combined imaging of both surface reflectance and fluorescence. Images are shown from a non-biological phantom of rhodamine between microscope cover slips. We also present an electro-optical technique to perform the signal processing necessary for SRSI in real time and with minimal computational power. By optically imaging a transverse (surface) dimension, spatially resolved spectral interferometry provides a way to circumvent the mechanical complexities of making precise, long travel, miniaturized translation mechanisms. This eliminates the greatest hurdle in implementing remote delivery (endoscopic) systems. Reducing the computational requirements enhances the speed of the system while simplifying its implementation. At the same time, combining different optical techniques leverages existing knowledge while providing additional structural information, a potentially powerful combination in diagnosis and treatment.

[1] A. F. Fercher, K. Mengedoht, and W. Werner, "Eye-Length Measurement by Interferometry with Partially Coherent Light," Opt. Lett., vol. 13, pp. 186-188, 1988.

[2] G. Hausler and M. W. Lindner, " Coherence Radar" and "Spectral Radar" - New Tools for Dermatological Diagnosis," Journal of Biomedical Optics, vol. 3, pp. 21-31, 1998.

[3] A. F. Zuluaga and R. Richards-Kortum, " Spatially Resolved Spectral Interferometry for Determination of Sub-surface Structure," Optics Letters, vol. 24, 1999. 


\section{ND-YAG AND CO2 LASER IRRADIATION OF APEX IN ENDODONTIC MICROSURGERY}

Sebastiano Tosto, ENEA Casaccia, Innovation Department via Anguillarese 301, ROMA, 00060, ITALY

T: +39-06-30483338, F: +39-06-30484729, tosto@casaccia.enea.it

Norberto Berna,

Marco Melis, Roma University The recent introduction of processing and diagnostic techniques like laser and surgical microscope has significantly modified procedures and materials for apical dental microsurgery. However, the local thermal shocks due to the laser irradiation can induce dimensional instability in the heat affected zone and then microcracks on the apex with possibility of persistent local inflammation; this result would be in contrast with the main purpose of the apicectomy, i.e. to eradicate irritant substances coming from the root canal system and eliminate the potential causes of inflammation in the apical zone. The paper aims to investigate comparatively by scanning electron microscopy (SEM) the morphological modifications of the new apex after laser irradiation at two infrared wavelengths, in particular as concerns the formation of microcracks and melting of dentine. The Nd-YAG laser used for the experiments operates at a frequency of $50 \mathrm{~Hz}$, with pulse length of $800 \mathrm{~ms}$ and maximum pulse energy of $0.7 \mathrm{~J}$. The maximum output power of the $\mathrm{CO} 2 \mathrm{cw}$ laser source was 6 W. 12 samples have been irradiated "in vitro" with various power levels and observed by SEM. The correlation between pulse fluence and surface modification of the heat affected zone is discussed in the paper. 
ADVANCES IN OPTICS

FOR BIOTECHNOLOGY, MEDICNNE AND SURGERY

\section{PHOTO-THERMAL PROFILING OF VASCULAR LESIONS UTILIZING TWO EXCTTATION WAVELENGTHS}

Boris Majaron, Beckman Laser Institute and Medical Clinic, University of California at Irvine 1002 Health Sciences Road East, Irvine, CA, 92612-1475, USA

T: (949) 824-4178,F: (949) 824-8413, majaron@bli.uci.edu

Wim Verkruysse, Beckman Laser Institute and Medical Clinic, University of California at Irvine, Irvine, $\mathbf{C A}$

Tom Milner, Biomedical Engineering Program, University of Texas, Austin, TX

Sam Tanenbaum, Department of Engineering, Harvey Mudd College; Claremont, CA

J. Stuart Nelson, Beckman Laser Institute and Medical Clinic, University of Califomia at Irvine, Irvine, $\mathbf{C A}$

In one-dimensional pulsed photo-thermal radiometry (PPTR), radiometric measurement of surface temperature evolution is used to reconstruct a transient temperature profile induced by absorption of a short laser excitation pulse in a layered sample. From the obtained temperature profiles and absorption properties of the sample constituents, longitudinal distribution of the chromophores in the sample can be assessed. This method has been recently introduced to the field of biomedical optics for depth determination of vascular lesions, such as port wine stains (PWS). The incentive is primarily to individually optimize the parameters of therapeutic laser pulse, and potentially also dynamic cryogen cooling.

When a pulsed dye laser, which is the laser of choice for therapeutic treatment of PWS lesions, is used as the excitation source, absorption in melanin heats up the epidermis (50-150 micrometers thick superficial layer of skin), in addition to causing the temperature rise in the highly vascular PWS layer beneath it. If the two layers are separated by only a marginal gap, the PWS lesion depth can not be determined due to inherently low spatial resolution of the method. We overcome this problem by using two excitation pulses, with wavelengths of 585 and $600 \mathrm{~nm}$. The two radiometric signals are combined to separate the contributions from melanin and blood absorption. These are reconstructed separately' to distinguish the temperature profiles in epidermis and in the vascular lesion, even when the two layers are virtually in contact. In addition, the oxygenation level of PWS blood can be estimated. 


\title{
ADVANCES IN OPTICS
}

FOR BIOTECHNOLOGY, MEDICINE AND SURGERY

\section{IMAGING AT MULTIPLE FREQUENCIES USING AMPLITUDE ONLY : A SURPRISINGLY BENEFICIAL APPROACH}

\author{
Vasilis Ntziachristos, University of Pennsylvania \\ D501 Richards Building, Philadelphia, PA, 19104-6089, USA \\ T: 215898 4342, F: 215898 1806, vasilis@mail.med.upenn.edu \\ A.G. Yodh, University of Pennsylvania \\ Britton Chance, University of Pennsylvania
}

The instrumentation simplicity of producing and detecting light of constant intensity makes constant wave (CW) tomography a very attractive technology for imaging of diffuse media in the NIR.

Conversely the superior performance of frequency domain or time domain techniques to image simultaneously absorption and scattering makes them many times the methods of choice for optical tomography (OT). The instrumentation complexity and increased cost involved with such implementations though, does not allow the employment of large array of sources and detectors, hence compromising resolution.

Here we investigate a hybrid approach, namely imaging at multiple frequencies using the photon wave intensity information only, which significantly simplifies instrumentation complexity of frequency domain imagers, offering the degree of practicality of $\mathrm{CW}$ imagers without compromising absorption and scattering differentiation. Since only intensity information needs to be retained, simple frequency differentiation with the use of appropriate band pass filters and subsequent rectification of the signals at the end of each band pass filter suffices to detect the intensity component at multiple-frequencies. We demonstrate that the diffuse wave amplitude at multiple frequencies carry absorbing and scattering differentiation information, similar to obtaining amplitude and phase information at a single frequency, therefore this virtue of frequency domain remains in this approach. We present image reconstructions of experimental measurements, which resolve simultaneously absorption and scattering objects, using the amplitude information only at multiple frequencies. Finally we compare $\mathrm{CW}$, single and multiple frequency reconstructions and demonstrate that only a few selected frequencies, spaced $200 \mathrm{MHz}$ apart, suffice under good signal to noise ratio conditions to quantitatively reconstruct inhomogeneous diffuse media. 


\title{
ADVANCES IN OPTICS \\ FOR BIOTECHNOLOGY, MEDICINE AND SURGERY \\ CARIES DETECTION USING POLARIZATION-SENSITIVE OPTICAL COHERENCE TOMOGRAPHY
}

\author{
Ujwal S. Sathyam, Lawrence Livermore National Laboratory \\ 7000 East Avenue; L-399, Livermore, CA, 94550, USA \\ T: 925-424-5852, F: 925-423-9457, ujwal@llnl.gov \\ Matthew J. Everett, Lawrence Livermore National Laboratory \\ Bill W. Colston, Jr., Lawrence Livermore National Laboratory \\ Luiz B. Da Silva, Lawrence Livermore National Laboratory
}

We present a non-invasive, non-ionizing imaging technique to detect dental caries using polarizationsensitive optical coherence tomography (PS-OCT). The system discriminates between normal and carious lesions by analyzing the polarization state of light backscattered from the enamel. Carious lesions are initiated by demineralization of the enamel which increases the optical scattering coefficient, thus depolarizing the incident light.

In this study, we first demonstrate the technique by differentiating between normal and artificially demineralized regions in a bovine enamel block. We then evaluate the system by generating in vitro images of extracted human teeth. Regions that appear to demineralized in the PS-OCT images are confirmed by histology to be carious or pre-carious lesions. This results of this study have demonstrated the great potential of PS-OCT to diagnose, characterize and monitor incipient carious lesions. This is the first demonstration of diagnosis of tissue state with OCT based on analysis of depolarization of light. 


\section{ADVANCES IN OPTICS}

FOR BIOTECHNOLOGY, MEDICINE AND SURGERY

\section{QUANTIFYING THE IMPORTANCE OF HIGH ANGLE SCATTERING EVENTS TO LIGHT-TRANSPORT THROUGH TURBID MEDIA MEASURED IN A BACKSCATTERING GEOMETRY}

\section{Murat Canpolat, Los Alamos National Laboratory}

MS E535, Biosciences and Biotechnology Group, Chemical Sciences and Technology Division Los Alamos National Laboratory, Los Alamos, NM 87545, Los Alamos, NM, 87544, US T: (505)665 45 37,F: (505)665 46 37, canpolat@lanl.gov Judith R. Mourant, Los Alamos National Laboratory

In the diffusion approximation, the collected light is a function of the reduced scattering ( 


\section{ADVANCES IN OPTICS}

FOR BIOTECHNOLOGY, MEDICINE AND SURGERY

\section{DIAGNOSIS OF OCULAR SURFACE NEOPLASIA BY OPTICAL SPECTRAL ANALYSIS}

Steven Chalfin, Department of Ophthalmology, University of Texas Health Science Center 7703 Floyd Curl Drive, San Antonio, TX, 78284-6230, USA

T: (210) 5678411, F: (210) 5678413 , chalfin@uthscsa.edu

Randolph D. Glickman, Department of Ophthalmology, University of Texas Health Science Center

Purpose: The diagnosis and management of ocular surface disease is a challenging task, due to widespread solar exposure of the population and resultant actinic damage. The ophthalmologist must currently rely on clinical intuition, long term follow-up with detailed drawings and photographs, and multiple biopsies which are inherently subject to sampling error. Management is complicated by the problem of obtaining adequate biopsy specimens from a small, delicate organ such as the eye. We have constructed an instrument which uses backscatter spectra to non-invasively diagnose lesions of the ocular surface.

Methods: Our initial studies, using a prototype instrument developed by physicists at the Los Alamos National Laboratory, demonstrated that it is possible to obtain optical signatures from the ocular surface. These signatures, which are dependent on scattering, absorption, and fluorescence characteristics of the tissue, appear to be quite sensitive to both the cellular structure and composition of the ocular surface. An instrument based on the Los Alamos design, with improved spectral resolution and faster sampling, is being used to obtain optical signatures from normal eyes and ocular surface lesions. Optical signatures are being correlated with histopathology of biopsy specipnens.

Results: Ocular optical signatures have been found to be highly reproducible, and sensitive to alterations in tissue characteristics. Sub-clinical lesions have been detected.

Conclusions: Optical signatures are sensitive to alterations in the ocular surface. We are enlarging the database of optical signatures and developing methods of spectral analysis which will discriminate between benign and malignant lesions.

Supported by grants from the San Antonio Area Foundation and Research to Prevent Blindness, Inc. 


\title{
ADVANCES IN OPTICS
}

FOR BIOTECHNOLOGY, MEDICINE AND SURGERY

\section{SPATIAL DISCRIMINATION OF OPTICALLY INDUCED ACOUSTIC SOURCES IN TISSUE PHANTOMS USING MATCHED FIELD PROCESSING}

\author{
John A. Viator, Oregon Medical Laser Center \\ 9205 SW Bames Road, Portland, OR, 97225, USA \\ T: 503.216.4093, F: 503.216.2422, javiator@ece.ogi.edu \\ Steve L. Jacques, Oregon Medical Laser Center \\ Scott A. Prahl, Oregon Medical Laser Center
}

\begin{abstract}
Acoustic waves can be induced by irradiating optical absorbers with stress confined laser pulses. We used a Q-switched, frequency-doubled Nd:YAG laser at $532 \mathrm{~nm}$ with a $4.75 \mathrm{~ns}$ pulse duration to excite an optical parametric oscillator (OPO). The OPO was tuned to $800 \mathrm{~nm}$. The laser energy , irradiated an absorbing sphere in an acrylamide gel tissue phantom. The resultant acoustic waves were sampled by a piezoelectric thin film transducer array. The predicted acoustic field was then modeled using ray theory. The experimental transducer signals and the modeled field were correlated using a linear matched field processor. The resulting correlation surface was used to localize the acoustic source. Two spheres were then irradiated, creating a composite acoustic field. The matched field processor was then used to determine the minimum separation of the two spheres for spatial discrimination. A third sphere was added to test the matched field processor for non-dipole acoustic sources. A search algorithm may be developed to aid in multiple source analysis.
\end{abstract}




\title{
ADVANCES IN OPTICS \\ FOR BIOTECHNOLOGY, MEDICINE AND SURGERY
}

\section{CHEMOMETRIC EXTRACTION OF OPTICAL PROPERTIES AND CHROMOPHORE CONCENTRATIONS FROM FREQUENCY DOMAIN PHOTON MIGRATION DATA}

\author{
Andrew J. Berger, Beckman Laser Institute and Medical Clinic \\ 1002 Health Sciences Road, Irvine, CA, 92612, USA \\ T: (949)824-4713, F: (949)824-8413, ajberger@bli.uci.edu \\ Vasan Venugopalan, Anthony J. Durkin, Tuan H. Pham, and Bruce J. Tromberg, Beckman Laser \\ Institute and Medical Clinic
}

The field of chemometrics is devoted to finding correlations between a parameter of interest and a series of related data measurements. The field of frequency domain photon migration (FDPM) is devoted (at its most basic level) to computing optical coefficients of a medium from a series of measurements, namely the phase and/or amplitude of a photon density wave. By combining these disciplines and applying chemometric techniques to the analysis of FDPM data, it should be possible to develop robust algorithms that successfully extract information even when the approximations used in standard diffusion analysis of the data are invalid. Such robustness could have important implications for the design and calibration of FDPM-based devices for medical diagnostics, where the measurement conditions cannot always be well-controlled.

In this initial study, we present the use of linear multivariate calibration for converting frequencydomain photon migration (FDPM) data into predictions of optical coefficients and chromophore concentrations. FDPM data from forty turbid, absorbing phantom samples (intralipid plus three dyes in water) were acquired in two geometries: infinite-boundary and cuvette transmission (1 cm pathlength). In both cases, the multivariate technique of partial least squares (PLS) was trained upon representative samples to extract accurate predictions of optical coefficients and dye concentrations from new samples. The infinite-boundary study shows that diffusion and PLS provide similar prediction accuracy when boundary conditions are simple; the cuvette experiment demonstrates the natural ability of PLS to handle boundary conditions that are difficult to describe analytically 


\title{
ADVANCES IN OPTICS
}

FOR BIOTECHNOLOGY, MEDICINE AND SURGERY

\section{OPTO-ACOUSTIC MONITORING OF BLOOD GLUCOSE}

\author{
Alexander A. Oraevsky, University of Texas Medical Branch \\ 301 University Blvd. MS 0456, Galveston, Texas, 77555-0456, USA. \\ T: 409-772-8348,F: 409-772-0751, alexander.oraevsky@utmb.edu \\ Andrey Bednov, UTMB \\ Kirill Larin, UTMB \\ Alexander Karabutov, UTMB
}

We propose a novel non-invasive glucose biosensor that employs laser optoacoustic measurements of profiles of the absorbed light energy distribution in human ear lobes. The presence of glucose dissolved in water changes the refractive index of any particles or fibers due to glucose properties as osmolyte. Therefore glucose may influence tissue (and blood) scattering properties. Initially, distributions of absorbed laser energy at $355 \mathrm{~nm}$ from a nanosecond Nd:YAG laser were measured in sclera of pigs and rabbits. The sclera is composed mainly of collagen fiber matrix filled with water, resulting in significant optical scattering and minimal absorption. Such tissue responds to osmolytes with maximum change in optical scattering. The level of glucose in sclera reaches $90 \%$ that of blood in several minutes after a stepwise jump of the blood glucose concentration. Therefore, changes of glucose concentration in blood may be related to changes of the optical scattering in sclera. Optical scattering in tissues increases when the laser wavelength decreases. Therefore, absolute value of the osmotic effect of glucose can be easier measured in the ultraviolet spectral range. The pulsed laser : optoacoustic technique permits accurate measurements of the effective optical attenuation coefficient in biological tissues. The experiments demonstrated that the optoacoustic method could be sufficiently sensitive to detect changes in optical scattering associated with physiologic changes in glucose concentration. The measured changes of scattering coefficient in the ultraviolet were about $2 \%$ per 10 millimole change in glucose concentration. Thus, our initial results demonstrated that normal glucose concentration in healthy humans of about 5 millimole could be distinguished from about 50 millimole in diabetic patients. 


\section{ADVANCES IN OPTICS \\ FOR BIOTECHNOLOGY, MEDICINE AND SURGERY \\ BURN DIAGNOSIS BY DIFFUSE PHOTON-DENSITY WAVE REFLECTANCE MEASUREMENTS}

Thorsten Spott, Norwegian University of Science and Technology (NTNU) currently: Beckman Laser Institute and Medical Clinic, UCI, Irvine, CA, 92612, USA

T: (949) 824 4712,F: (949) 824 8413, thorsten@fysel.ntnu.no

Tuan Pham, Beckman Laser Institute and Medical Clinic

Lars $\mathrm{O}$. Svaasand, Norwegian University of Science and Technology

Bruce J. Tromberg, Beckman Laser Institute and Medical Clinic

Burn wounds are characterized by layers of thermally denatured and viable tissue. We are developing an optical tool that allows for the non-invasive, quantitative assessment of burn depth and tissue status. Our approach to recover information about the structure of such layered tissues is based on the measurement of the diffuse reflectance of photon-density waves (PDW). These waves are established by irradiating the tissue with intensity modulated light. PDW propagation properties depend on the modulation frequency of the light as well as the optical properties and the thickness of the tissue layers. The interference of partial waves propagating in the respective tissue layers becomes manifest in the amplitude and the phase of the diffusely reflected light. By varying the modulation frequency, the probing depth can be influenced. We have developed a plane-wave model for the mathematical description of the underlying phenomena, which translates into a measurement setup that avoids contact with the tissue surface. In this study, theoretical simulations are complemiented by experimental results from in vivo measurements on rats, using light of different wavelengths in the near-infrared region and modulation frequencies ranging from $10 \mathrm{MHz}$ to $1.5 \mathrm{GHz}$. We show that the increase in scattering in the denatured material leads to characteristic phase shifts in the diffusely reflected light. This approach allows us to measure the burn thickness with a resolution of about $0.5 \mathrm{~mm}$ to a depth of up to $10 \mathrm{~mm}$ in typical tissues. 
ADVANCES IN OPTICS

FOR BIOTECHNOLOGY, MEDICINE AND SURGERY

\title{
OPTO-ACOUSTIC CELL PERMEATION
}

\author{
Steven R. Visuri, Lawrence Livermore National Laboratory \\ P.O. Box, L-399, Livermore, CA, 94551, USA \\ T: 925-424-3517, F: 925-424-2778, visuri@llnl.gov
}

Optically generated acoustic (pressure) waves have been used to temporarily permeate biological cells. This technique may be useful for enhancing transfection of DNA into cells or enhancing the absorption of locally delivered drugs. A diode-pumped frequency-doubled Nd:YAG laser operating at $\mathrm{kHz}$ repetition rates was used to produce a series of acoustic pulses. The laser energy was deposited into an absorbing dye where an acoustic wave was formed by thermoelastic expansion. A PVDF hydrophone was used to measure generated pressures.

These acoustic waves were transmitted to cultured and plated cells. The cell media contained a selection of normally-impermeable fluorescent-labeled dextran dyes. Following treatment with the opto-acoustic technique, cellular incorporation of dyes, up to 40,000 Molecular Weight, was noted. Control cells that did not receive opto-acoustic treatment had unremarkable dye : incorporation. Uptake of dye was quantified via fluorescent microscopic analysis. Trypan Blue. membrane exclusion assays confirmed the vitality of cells following treatment. This method of enhanced drug delivery has the potential to dramatically reduce required drug dosages and associated side effects and enable revolutionary therapies. 


\title{
ADVANCES IN OPTICS \\ FOR BIOTECHNOLOGY, MEDICINE AND SURGERY \\ POLARIZATION SPECTROSCOPY OF CERVICAL EPITHELIUM FOR PRE- CANCER DETECTION
}

\begin{abstract}
Konstantin Sokoloy, Biomedical Engineering
The University of Texas at Austin, Austin, Texas, 78712, USA

T: (512) 471 7440, F: (512) 475 8854, kostia@mail.utexas.edu

Kirk Gossage, Biomedical Engineering, The University of Texas at Austin

Rebekah Drezek, Biomedical Engineering, The University of Texas at Austin

Rebecca Richards-Kortum, Biomedical Engineering, The University of Texas at Austin

Light elastically scattered by biological tissue contains information about scatterer sizes.

Perelman [1] suggested that the scatterer size distribution can be retrieved from scattering spectra using Mie theory, providing a tool to instantly assess nuclear size distributions. Detection of epithelial pre-cancers using this approach is limited by strong stromal scattering which must be separated from epithelial scattering. Here, we compare scattering spectra obtained with polarized : and unpolarized illumination/detection. Polarized illumination/detection reduce the diffuse scattering background, enhancing the size-dependant scattering signature of the epithelium.
\end{abstract}

Scattering spectra were obtained from phantoms and tissues of increasing complexity. Suspensions of uniform polystyrene beads and cells were placed atop a diffusely scattering substrate to simulate stromal background. The use of polarized illumination/detection allows direct observation of the size-dependant periodic Mie scattering, without additional processing necessary to extract these components from unpolarized spectra. Both backscattering and forward scattering contribute to the scattering spectra. To characterize the contribution of cell nuclei BSA was used to reduce the index mismatch between cytoplasm and extra-cellular fluid; this resulted in a decrease in the portion of the spectrum attributed to the cytoplasm. Next, acetic acid was added to increase nuclear scattering, resulting in an increase in the portion of the spectrum attributed to the nuclei. Both the diffuse background and hemoglobin absorption are significantly reduced in spectra obtained from cervical biopsies using polarized illumination and detection. We observed distinct differences in scattering profiles of normal and pre-cancerous biopsies. Theoretical modeling to relate these changes to nuclear size distributions is currently underway.

1. L.T. Perelman, V. Backman, M. Wallace, G. Zonios, R. Manoharan, A. Nusrat, S. Shields, M. Seiler, C. Lima, T. Hamano, I. Itzkan, J. Van Dam, J.M. Crawford, and M.S. Feld, Phys. Rev. Lett. 80, 627-630 (1998). 


\title{
ADVANCES IN OPTICS \\ FOR BIOTECHNOLOGY, MEDICINE AND SURGERY
}

\section{POLARIZED LIGHT PROPAGATION THROUGH TISSUE AND TISSUE PHANTOMS}

\author{
Vanitha Sankaran, Lawrence Livermore National Laboratory \\ P.0. Box 808, L-399, Livermore, CA, 94551, USA \\ T: 925-424-3101, F: 925-424-2778, sankaran1@llnl.gov \\ Joseph T. Walsh, Jr., Northwestern University \\ Duncan J. Maitland, Lawrence Livermore National Laboratory
}

Imaging through biologic tissue relies on the discrimination of weakly scattered from multiply . scattered photons. The degree of polarization can be used as the discrimination criterion by which to reject multiply scattered photons. Polarized light propagation through biologic tissue is typically studied using tissue phantoms consisting of dilute aqueous suspensions of polystyrene microspheres. We have previously shown that, although such phantoms are designed to match the macroscopic scattering properties of tissue (i.e., the scattering coefficient, $u_{s}$, and scattering anisotropy, g), they do not accurately represent biologic tissue for polarization-sensitive studies. In common tissue phantoms, such as dilute Intralipid and dilute 1-um-diameter polystyrene microsphere suspensions, we have found that linearly polarized light is depolarized more quickfy than circularly polarized light. In tissue, however, where scatterers are often located in close proximity to one another, circularly polarized light is depolarized similar to or more quickly than linearly polarized light. We demonstrate here that polarized light propagates differently in densely packed rather than dilute microsphere suspensions. This behavior, which may account for the differences seen between polarized light propagation in common tissue phantoms versus biologic tissue, may be attributed partially to coherent interference between closely packed scatterers .

The depolarization of both linearly and circularly polarized light was investigated using $0.48 \mathrm{um}$, 2.092 um, and 9.14-um-diameter polystyrene spheres suspended in water and in porcine adipose tissue. The results indicate that for dilute suspensions of microspheres where independent scattering is assumed, the degree of linear and circular polarization decrease as scatterer density increases. Linearly polarized light is depolarized more quickly than circularly polarized light for each particle size. At a critical density of scatterers, however, the degree of polarization begins to increase with increasing scatterer density. For these dense suspensions, linearly and circularly polarized light propagate similarly and thus mimic biologic tissue more accurately than the filute suspensions. 


\title{
ADVANCES IN OPTICS \\ FOR BIOTECHNOLOGY, MEDICINE AND SURGERY
}

\section{TWO-PHOTON FLUORESCENCE MICROSCOPY IN TURBD MEDIA}

\author{
Andrew Dunn, Beckman Laser Institute \\ University of California, Irvine, CA, 92612, USA \\ T: 949-824-4713, F: 959-824-8413, adunn@bli.uci.edu \\ Vincent Wallace, Beckman Laser Institute \\ Mariah Coleno, Beckman Laser Institute \\ Bruce Tromberg, Beckman Laser Instutite
}

Two-photon fluorescence microscopy has shown promise for noninvasive imaging of subsurface features. However, the ability to penetrate deeply into tissues using two-photon fluorescence imaging is limited by tissue scattering. The effects of scattering on the generation and collection of two-photon fluorescence in turbid samples have been studied both experimentally and theoretically. We have developed a Monte Carlo model that allows us to study the effects of experimental parameters such as numerical aperture, pulse width, repetition rate and tissue optical properties, on the imaging performance at multiple depths. The model results show good agreement with experimental measurements of fluorescent microspheres embedded in intralipid.

The predicted and measured widths of the spatial point spread function show that the point spread function does not broaden significantly as the depth of the image plane increases. The amplitude of the detected signal with depth was found to decay exponentially with a slope that varies with optical properties and beam parameters. Therefore the maximum imaging depth was found to be limited by a loss of signal rather than a loss of resolution. The model predicts that the maximum imaging depth is about 500 um for a typical epithelial tissue stained with a fluorophore such as phthalocyanine, assuming a numerical aperture of 1.3 , a pulse width of 100 fs, and a pulse repetition rate of $76 \mathrm{MHz}$. Measurements of thick tissue sections confirm the model predictions. The measurements and model also suggest that it is possible to extract tissue optical properties from the form of the exponential decay of the two-photon fluorescence signal. 


\title{
ADVANCES IN OPTICS \\ FOR BIOTECHNOLOGY, MEDICINE AND SURGERY
}

\section{MICROSTRUCTURE IMAGING OF IN VIVO HUMAN SKIN TISSUE BY OPTICAL COHERENCE TOMOGRAPHY}

\author{
S. H. Xiang, Beckman Laser Institue and Medical Clinic, University of California at Irvine \\ 1002 Health Science Road East, Irvine, CA, 92612, USA
}

T: (949) 824-4713,F: (949) 824-8413, shxiang@bli.uci.edu

Y. Zhao, Beckman Laser Institue and Medical Clinic, University of California at Irvine

Z. Chen, Beckman Laser Institue and Medical Clinic, University of California at Irvine

J. S. Nelson, Beckman Laser Institue and Medical Clinic, University of California at Irvine

Optical Coherence Tomography (OCT) is a new biomedical technology that produces cross sectional images of biological tissues with micrometer resolution. During the past few years, OCT has been widely used for imaging transparent tissues, such as the eye. However, relatively little progress has been made in imaging highly scattering tissues, such as human skin. The major problem to be overcome is the coherent noise (such as speckle) which is introduced by interference from multiple scatters at different path lengths inside the tissue. In a practical OCT system, coherent noise results in a low signal-to-noise ratio (SNR) making it difficult to resolve small structural features or boundaries between different objects within the tissue. A new OCT system for imaging in vivo human skin has been built with the advantages of $A$ line dynamic focussing and multiple array detection. To reduce coherent noise and increase the SNR, InGaAs detectors with eight array elements have been applied to detect the coherence back scattered it signals. In order to enhance the robustness of dynamic focussing in axial directions, a new crossed-roller bearing based voice-coil scanning system has been employed in the system. A $2.4 \mathrm{~mm}$ (width) $\times 1.5 \mathrm{~mm}$ (depth) OCT image with a pixel resolution of 6um (lateral) X $2 \mathrm{um}$ (axial) has been obtained with a SNR improvement of 3 times. The coherence optical image bas been compared to histology and the results indicated a strong correlation between the two modalities. 


\title{
ADVANCES IN OPTICS \\ FOR BIOTECHNOLOGY, MEDICINE AND SURGERY
}

\section{MONTE CARLO MODELING OF POLARIZED LIGHT PROPAGATION IN MULTIPLE SCATTERING MEDIA}

\author{
Sebastian Bartel, State University of New York \\ 450 Clarkson, Brooklyn, NY, 11203, USA \\ T: (718) 270 4561, F: (718) 270 3313, SBartel@netmail.hscgklyn.edu
}

A. H. Hielscher, State University of New York

Recently, the concept of Mueller matrices, commonly used to describe non-depolarizing optical . elements, has been generalized to the diffuse backreflection from multiply scattering media. Several groups have embraced the idea of characterizing a randomly scattering media by its backscattering Mueller matrix. This $4 \times 4$ matrix operator completely determines the transformation of any incident polarization state. Each element of the matrix may be obtained experimentally by a series of measurements that involve point illuminations and recording of 2 dimensional surface-intensity maps[1] [2].

Some of the matrix elements show very characteristic, azimuthal symmetries. The distinct differences in the symmetry of these patterns for different types of particle suspensions strongly encourage the idea of identifying a medium by its Mueller matrix. Researchers have proposed theoretical models based on simple geometry considerations, that qualitatively describe the azimuthal varying intensity distributions. However, a mathematical model capable of describing the patterns quantitatively has not been provided, so far.

We have implemented a Monte Carlo simulation that fully considers polarization dependent scattering according to Mie theory and thus traces individual photons and their respective Stokes vector as they undergo multiple scattering. By integrating over a sufficiently large number of photon trajectories, we are able to determine the effective backscattering Mueller matrix of an ensemble of randomly distributed particles. We find excellent agreement between experimental and numerical results for different particle suspensions. Both azimuthal and radial feature for all 16 elements are captured by the simulations.

[1] Brent D. Cameron, M. J. Rakovic, M. Mehrobeoglu, G. Kattawar, S. Rastegar, L. V. Wang, G. Cote Measurement and Calculations of the Two-Dimensional Backscattering Mueller Matris of a Turbid Medium', Opt. Lett 23, 485-487 (1998)

[2] A. H. Hielsche, Angelia A. Eick, J. R. Mourant, D. Shen J. P. Freyer, I. J. Bigio Diffuse Backscattering Mueller Matrices of Highly Scattering Media', Opt. Exp. 1 No.13, 441-453 (1997) 


\section{ADVANCES IN OPTICS \\ FOR BIOTECHNOLOGY, MEDICINE AND SURGERY \\ IN VTVO REFLECTANCE SPECTROSCOPY OF OVARIAN TISSUE}

Urs Utzinger, The University of Texas at Austin

Biomedical Engineering Program, Austin, TX, 78712, USA

T: (512) 471 2398,F: (512) 471 0616, utzinger@mail.utexas.edu

Molly Brewer, Department of Gynecology, The University of Texas Medical School, Houston

Rebecca Richards-Kortum, The University of Texas at Austin

Background and Objective: Ovarian cancer has the highest mortality of any gynecologic cancers. Unfortunately effective screening tools to identify early disease do not exist at the present time. The objective of this study was to explore whether reflectance spectroscopy can differentiate normal ovary, benign neoplasms and ovarian cancer.

Materials and Methods: Ovarian tissue reflectance spectra were measured from 390-600 nm at three source-detector separations (SDS) $(1.1,2.1$ and $3 \mathrm{~mm}$ ) in vivo from 74 sites in 18 patients undergoing oophorectomy. Following spectroscopic measurement, areas were biopsied and histopathologic diagnosis was obtained for gold standard reference. Parameters with most statistically significant differences of normal ovary, benign neoplasms and ovarian cancers were analyzed. Algorithms to (1) differentiate normal ovary from benign neoplasms and cancers (screening) and (2) differentiate ovarian cancers from benign neoplasms and normal ovary (diagnostic) were developed and evaluated.

Results: Most promising parameters for ovarian tissue classification include the reflectance intensity from $540 \mathrm{~nm}$ to $580 \mathrm{~nm}$ at a SDS of $1.1 \mathrm{~mm}$, the slope of the reflectance spectrum from $490 \mathrm{~nm}$ to $520 \mathrm{~nm}$ at a SDS of $1.1 \mathrm{~mm}$, the slope from $510 \mathrm{~nm}$ to $530 \mathrm{~nm}$ at a SDS of $2.1 \mathrm{~mm}$ and the slope from $510 \mathrm{~nm}$ to $530 \mathrm{~nm}$ at a SDS of $3 \mathrm{~mm}$. Algorithms developed from all pairwise combinations of these parameters resulted in an average sensitivity of $86 \%+1-6 \%$ and an average specificity of $79 \%+1-5 \%$ to separate normal ovarian findings from benign neoplasms and cancers and an average sensitivity of $86 \%+1-4 \%$ and an average specificity of $80 \%+1-8 \%$ to separate ovarian cancers from benign neoplasms and normal findings.

Conclusions: Reflectance spectroscopy has the potential to identify and differentiate normal ovarian structures, benign neoplasms and ovarian cancers and should be explored further. 
ADVANCES IN OPTICS

FOR BIOTECHNOLOGY, MEDICINE AND SURGERY

\title{
NEAR IR DIFFUSE LIGHT STUDIES OF BLOOD FLOW AND HEMOGLOBIN SATURATION IN MICE TUMORS DURING PHOTODYAMIC THERAPY
}

\author{
Joseph P. Culver, Department of Physics \& Astronomy, University of Pennsylvania \\ 209 S. 33rd St., Philadelphia, PA, 19104, USA \\ T: 215-573-3463,F: 215-573-6391, culver@soll.1rsm.upenn.edu \\ Cecil Cheung, Teodor Vulcan, Department of Physics \& Astronomy \\ Cindy Skema, Joseph Freidberg, Department of Surgery. \\ Arjun Yodh, Department of Physics \& Astronomy
}

Hypoxia and microvascular damage induced by Photodynamic therapy are important to the mechanisms of tumor necrosis and the efficacy of the treatments. These processes can be followed during PDT treatments using several different real time noninvasive probes. For example, hypoxia has been monitored using electrodes to measure tissue oxygen tension. In other studies, Laser Doppler and Optical Doppler Tomography techniques were used to monitor microvascular damage by measuring blood flow on tumor surfaces. In general these noninvasive probes can only probe the surface $(<1 \mathrm{~mm})$ properties of the tumors. We have developed a new near infrared probe to simultaneously monitor hemoglobin saturation, concentration and flow speed in deep tissues. In vivo measurements of PDT treatments of tumors in mice will be presented.

The noninvasive measurements employ diffuse light to probe deep tissues permitting the entire tumor volume to be monitored. The static optical properties are measured with $70 \mathrm{MHz}$ diffuse photon density waves at 786 and $830 \mathrm{~nm}$. Treatment induced changes in the hemoglobin saturation are followed by monitoring the absorption coefficients at the two wavelengths. The dynamic optical properties are monitored using diffuse light correlation spectroscopy at $800 \mathrm{~nm}$. Changes in the blood flow are obtained from the correlation decay times. The two optical techniques are co-registered using multiple sources (4 or 9) and multiple detectors (4). The complete sets of source detector measurements provide both average values and local values for the changes in the tumor. In vivo studies were conducted on human tumors grown on mice. The tumors were prepared by injecting Photofrin and treated using $630 \mathrm{~nm}$ radiation. The observations clearly reveal changes in the flow, hemoglobin saturation and blood volume during the light treatment. 


\title{
ADVANCES IN OPTICS \\ FOR BIOTECHNOLOGY, MEDICINE AND SURGERY
}

\section{"BRIDGING THE GAP BETWEEN PHOTON MIGRATION IMAGING AND FLUORESCENCE MICROSCOPY"}

\author{
Britton Chance, University of Pennsylvania \\ D501 Richards Bldg, Philadelphia, PA, 19104, USA \\ T: 215-898-7159, F: 21-898-1806, chance@mail.med.upenn.edu \\ K.Kang, University of Maryland \\ S. Zhou, University of Pennsylvania
}

"Bridging the gap between photon migration imaging and fluorescence microscopy" B. Chance, K.Kang, S. Zhou The limited resolution of photon diffusion imaging combined with a high sensitivity and specificity derived from the multiplicity of intrinsic chromophores in tissues leads to many uses in medicine. Here we describe photon diffusion devices to detect small subsurface objects in tissues. We have therefore explored the limitations of object detection, not imaging, of small objects with amplitude cancellation devices. The photon diffusion wave is long compared to the distances within the tissue of interest; near field observations are possible and the diffraction limitations do hold. In order to study this phenomenon, we have used $50 \mathrm{MHz}$ modulated light, in phase and anti-phase, end have observed amplitude nulls of $40 \mathrm{~dB}$ and sensitivity to detect motion of $46 \% \mathrm{~mm}$. (Simulation gives $>100 \% \mathrm{~mm}, \mathrm{Kang}$ ) An $0.8 \% \mathrm{~mm}$ rod gives a sensitivity of $2.6 \% \mathrm{~mm}$ with a noise of level $0.1^{\circ} .60 \mathrm{~Hz}$ modulation of the in and out of phase optical fields at $0^{\circ}$ and $90^{\circ}$ provides a electronic scan of null planes. In order to provide continuity between in depth detection and the surface detection, we can coordinate the spot excitation of fluorescent signals by a flying spot system with the axis of the phased array in-depth detector. The integrated detection system expected to produce a seamless coupling from surface fluorescence imagery to in-depth fluorescence localization, and with suitable target molecular beacons, characterization of small objects. 


\section{ADVANCES IN OPTICS \\ FOR BIOTECHNOLOGY, MEDICINE AND SURGERY}

\section{SPECTRAL VARIATION OF INFRARED ABSORPTION COEFFICIENT IN PULSED PHOTOTHERMAL PROFILING OF BIOLOGICAL TISSUE.}

Wim Verkruysse, Beckman Laser Institute and Medical Clinic, 1002 Health Sciences Rd. East, Irvine, Califomia, 92612, USA

T: (949) 824 4770, F: (949) 8248413 , wverkru@bli.uci.edu

Boris Majaron, Beckman Laser Institute and Medical Clinic, Irvine, CA.

B. Samuel Tanenbaum, Harvey Mudd College, Claremont, CA.

Thomas E. Milner, University of Texas at Austin, Austin, TX.

J. Stuart Nelson, Beckman Laser Institute and Medical Clinic, Irvine, CA.

Pulsed photothermal radiometry was recently introduced to non-invasively determine spatial distribution of chromophores such as melanin and blood in human vascular skin lesions. In this method, a subtherapeutic laser pulse induces a temperature increase in the chromophores. The resulting temporal evolution of thermal radiometric signal, is recorded using an infra-red camera after which the initial spatial temperature profile can be reconstructed using an inversion algorithm.

In a commonly used detection bandwidth of 3 


\title{
ADVANCES IN OPTICS
}

FOR BIOTECHNOLOGY, MEDICINE AND SURGERY

\section{THE COMBINATION OF FLUORESCENCE AND REFLECTANCE SPECTROSCOPIES AS A TOOL FOR THE DETECTION OF PREMALIGNANCIES IN THE ESOPHAGUS AND THE STOMACH}

\author{
Irene Georgakoudi, Massachusetts Institute of Technology \\ G.R. Harrison Spectroscopy Laboratory, 77 Massachusetts Ave. Rm 6-014, Cambridge, MA, 02139, \\ USA \\ T: (617)258-9487, F: (617)258-6586, ireneg@mit.edu \\ Qingguo Zhang, Markus G. Mueller, M.I.T. G.R. Harrison Spectroscopy Laboratory \\ Brain C. Jacobson, Jonathan Glickman, Jacques Van Dam, Brigham and Women's Hospital, Boston, \\ MA \\ Michael S. Feld, M.I.T. G.R. Harrison Spectroscopy Laboratory
}

We employ the combination of reflectance and laser induced autofluorescence spectroscopies as a non-invasive tool for the detection of malignant and premalignant lesions in the esophagus and the stomach. Tissue autofluorescence and white light reflectance spectra are obtained in vino during endoscopy using a fiber-based fast excitation emission matrix (EEM) instrument. Autofluorescence spectra in the 350-750 nm range are recorded at eleven excitation wavelengths between 337 and 650 $\mathrm{nm}$. A set of spectra is acquired in approximately $0.5 \mathrm{~s}$.

It is difficult to extract useful diagnostic information in the esophagus and the stomach from the autofluorescence spectra alone, since tissue scattering and absorption lead to significant distortions. However, the reflectance spectra can be used to account for such distortions and, thus, to obtain the intrinsic tissue autofluorescence. Preliminary studies including a small number of patients indicate that there are significant differences in the intensity and the spectral lineshape of the intrinsic fluorescence of normal, Barrett's and high grade dysplastic esophageal tissues. Similarly, the intrinsic autofluorescence spectrum of normal gastric mucosa is different from that of mucosa with gastritis, which in turn is distinct from the spectrum of mucosa with intestinal metaplasia. Such differences could arise as a result of the biochemical and architectural changes that occur in neoplastic tissues and are often invisible during endoscopy. Therefore, it appears that the combination of fluorescence and reflectance spectroscopies could be a very sensitive tool for the diagnosis of cancerous and precancerous lesions in the gastrointestinal tract. 
ADVANCES IN OPTICS

FOR BIOTECHNOLOGY, MEDICINE AND SURGERY

\section{QUANTIFICATION OF FETAL CEREBRAL BLOOD OXYGENATION IN UTERO BY FREQUENCY DOMAIN NIR SPECTROSCOPY : SEMI-INFINITE \& TWO-LAYER \\ APPROXIMATION.}

Regine Choe, Department of Physics \& Astronomy, University of Pennsylvania 209 S. 33rd St., Philadelphia, PA, 19104, U.S.A

T: (215)898-3296, F: (215)898-1806, rgchoe@mail.sas.upenn.edu

Gargi Vishnoi, Department of Biochemistry \& Biophysics, University of Pennsylvania Nirmala Ramanujam, Department of Biochemistry \& Biophysics, University of Pennsylvania: Britton Chance, Department of Biochemistry \& Biophysics, University of Pennsylvania A.G. Yodh, Department of Physics \& Astronomy, University of Pennsylvania

An attempt has been made to measure fetal cerebral blood oxygenation in utero using a frequency domain NIR spectroscopy. Studies have been performed on human subjects during the elective Cesarean sections. The system records the amplitude and phase from 750 and $780 \mathrm{~nm}$ light sources which propagates through the tissue in reflectance mode at source detector separations of $7 \mathrm{~cm}$ and $3 \mathrm{~cm}$. The pre-partum measurements were made on maternal abdomen (post-epidural) and post-partum measurements were on infant's forehead before (pre-cord) and after (post-cord) the umbilical cord was detached.

The data were fitted to the solution of diffuse equation for semi-infinite geometry to calculate absorption coefficient $\left(\mu_{2}\right)$ and reduced scattering coefficients $\left(\mu_{s}\right)$. The blood volume (BV) and saturation (BS) were calculated based on $\mu_{z}$ at each wavelength. The averaged values for $\mu_{2}, \mu_{s}^{\prime}$, BV and BS at each stage based on semi-infinite approximation are presented. The correlations between calculated blood saturation and cord blood gas saturation at various stages are also presented.

At late gestation, the separation between fetal head and the uterine wall is almost negligible so that the presence of amniotic fluid may be ignored. Therefore, the in-utero system may be approximated as a two-layer system which consists of maternal abdomen and fetal head with appropriate $\mu_{\mathrm{s}}$ and $\mu_{s}$. Preliminary Monte Carlo simulation with $10^{6}$ photons for two layer system has been carried out and fitted using the semi-infinite approximation. It was observed that the upper layer significantly contributes to the total effective $\mu_{\mathrm{a}}$ as compared to the lower layer. Studies are in progress to establish the limits of semi-infinite algorithm. Two-layer analytic approximations are also being tested and implemented to the post-epidural data at $3 \mathrm{~cm}$ and $7 \mathrm{~cm}$ source detector separation. 
ADVANCES IN OPTICS

FOR BIOTECHNOLOGY, MEDICINE AND SURGERY

\title{
CLINICAL CHARACTERIZATION OF COLONIC MUCOSAL LESIONS IN VIVO USING AUTOFLUORESCENCE AND DELTA-AMINOLEVULINIC ACD SENSITIZATION
}

\author{
Charlotta Eker, Lund University Medical Laser Centre, Department of Physics, Lund Institute of \\ Technology \\ P.O. Box 118, SE-221 00 Lund, Sweden \\ T: +46-46-2223120, F: +46-46-2224250, lotta@fysik.lth.se
}

Edgar Jaramillo, Division of Internal Medicine, Karolinska Hospital, Stockholm, Sweden

Stefan Andersson-Engels, Lund University Medical Laser Centre, Department of Physics, Lund.

Institute of Technology, Lund, Sweden

Eduard Jonas, Division of Internal Medicine, Karolinska Hospital, Stockholm, Sweden

Katarina Svanberg, Lund University Medical Laser Centre, Department of Oncology, Lund University Hospital, Lund, Sweden

Background .

Laser-induced fluorescence (LIF) is a method of great interest in the detection and characterization of malignant lesions in several types of biological tissue. We wanted to study if LIF can be used to distinguish adenomatous from hyperplastic polyps in colon tissue in real time during colonoscopy.

Patients

A total of 139 patients have been measured with LIF. Spectra from 69 adenomas, 135 normal sites and 47 hyperplastic polyps were obtained with a point monitoring system. Seventy-one of the patients had been given a low dose of ALA as a photosensitizer before the examination.

Methods

Fluorescence spectra were collected in vivo during colonoscopy following sequential excitation with light of 337 or $405 \mathrm{~nm}$ wavelength. A partial least squares (PLS) analysis was used for the evaluation. The fluorescence spectra were divided in a training set and a validation set. A PLS calibration was performed on the training set to define a model that will distinguish adenomatous from hyperplastic polyps. Normal mucosa that usually can be easily identified by the endoscopist was not included in the model.

Results

A preliminary evaluation shows that a high specificity (95\%) but a rather low sensitivity (47\%) is achieved using $337 \mathrm{~nm}$ excitation. An even lower sensitivity is achieved using $405 \mathrm{~nm}$ excitation and ALA. However, all data is not yet included, and a more careful analysis, possibly with logistic regression, needs to be performed before any firm conclusions can be drawn from this study. This work is under progress and will be included in the presentation at the conference. 


\title{
ADVANCES IN OPTICS \\ FOR BIOTECHNOLOGY, MEDICINE AND SURGERY
}

\section{MULTI-WAVELENGTH DETERMINATION OF FAT OPTICAL PROPERTIES USING FREQUENCY DOMAIN PHOTON MIGRATION}

\author{
Charlotta Eker, Lund University Medical Laser Centre, Department of Physics, Lund Institute of \\ Technology \\ P.O. Box 118, SE-221 00 Lund, Sweden \\ T: +46-46-2223120,F: +46-46-2224250, lotta@fysik.lth.se \\ Natasha Shah, Beckman Laser Institute and Medical Clinic, University of California, Irvine \\ Tuan Pham, Beckman Laser Institute and Medical Clinic, University of California, Irvine \\ Bruce Tromberg, Beckman Laser Institute and Medical Clinic, University of California, Irvine
}

Background

Frequency-Domain Photon Migration (FDPM) is a non-invasive optical technique that utilizes intensity-modulated, near-infrared light to measure tissue absorption and scattering properties. This study examined the optical properties of fat and the possibility of using the absorption properties derived from FDPM measurements to calculate the fat content of tissue. This is potentially interesting for the in viro diagnosis of various tumor types in female breast tissue. Earlier studies have shown that it is feasible to measure the oxy-and deoxy-hemoglobin and water contents in tissue with this technology.

Materials and Methods

All measurements were performed using a diode-laser-based FDPM device optimized for clinical optical property studies. This system presently employs five wavelengths $(674,803,849,894$ and 915 $\mathrm{nm}$ ) and multiple modulation frequencies $(50 \mathrm{kHz}-1 \mathrm{GHz})$. Measurements were made on a fat phantom (lard) at different temperatures, as well as on breast tissue of a healthy volunteer. A two-fiber setup was used to measure the backscattered light at a distance of $8-16 \mathrm{~mm}$ from the source fiber. A set of measurements yields absorption and reduced scattering coefficients at each wavelength. From the absorption coefficients, extinction coefficients for fat can be calculated, and these can be used to calculate fat concentration from breast measurements.

Results

The optical properties of fat could be determined at the five wavelengths employed. It could be seen that scattering, but not absorption, is highly dependent on the temperature. The absorption coefficients resulting from measurements of healthy breast tissue in vivo could be used to calculate oxy- and deoxy-hemoglobin as well as water- and fat concentrations. The obtained values corresponded well to literature values. 


\title{
ADVANCES IN OPTICS \\ FOR BIOTECHNOLOGY, MEDICINE AND SURGERY
}

\section{DEPTH-RESOVELD BIREFRINGENCE IMAGING IN THE EYE WTTH POLARIZATION- SENSITIVE OPTICAL COHERENCE TOMOGRAPHY}

\author{
Mathieu G. Ducros, University of Texas at Austin Biomedical Engineering Program \\ Buiding ENS, Room 610, University of Texas at Austin, Austin, TX, 78712, USA \\ T: 512-471-4703, F: 512-475-8854, mathieu_ducros@mail.utexas.edu \\ Johannes F. de Boer, Beckman Laser Institute and Medical Clinic \\ Huai-En Huang, Beckman Laser Institute and Medical Clinic \\ H. Grady Rylander, University of Texas at Austin Biomedical Engineering Program \\ Thomas E. Milner, University of Texas at Austin Biomedical Engineering Program
}

Polarization-sensitive optical coherence tomography (PSOCT) is a recently developed imaging technique that allows depth-resolved measurement of birefringence in turbid biological tissues. The light backreflected from the tissue interferes with that from the reference path and is coherently detected in two orthogonal polarization channels. The two signals are digitized and the four Stokes parameters (I, Q, $U$ and V) of the backreflected light are computed for each longitudinallateral position in the sample. From the measured Stokes parameters, an estimate of the relative phase retardation between the two orthogonal polarizations can be determined.

In the present work, the comea and retina of New-Zealand white rabbit were imaged ex-vivo with PSOCT. The eyes were enucleated, images acquired within 6 hours post-mortem, and histology performed.

Images of the Stokes parameters of light backreflected from the comeal stroma showed significant local variations in the polarization state, possibly due to local changes in stromal structure. Depth-: resolved Stokes parameter images of light backreflected from the retina were acquired. A birefringent layer was observed at a position consistent with the known location of the nerve fiber layer (NFL). The local thickness of the birefringent layer determined with PSOCT was in good agreement with values determined histologically.

PSOCT has the potential to enhance the accuracy of current NFL thickness measurement methods, thus providing a more reliable method for early diagnosis of glaucoma. 


\section{ADVANCES IN OPTICS \\ FOR BIOTECHNOLOGY, MEDICINE AND SURGERY \\ ALGORITHMS FOR 3D LOCALIZATION AND IMAGING USING NEAR-FIELD DIFFRACTION TOMOGRAPHY WITH DIFFUSE LIGHT}

Turgut Durduran, Department of Physics \& Astronomy, University of Pennsylvania 209 S. 33rd Str, DRL, Philadelphia, PA, 19104, USA T: 215-573-3463, F: 215-573-6391, durduran@mail.sas.upenn.edu

J. P. Culver, M. J. Holboke, X. D. Li, Leonid Zubkov, Department of Physics \& Astronomy, University of Pennsylvania

B. Chance, Department of Biophysics and Biochemisty, University of Pennsylvania

Deva N. Pattanayak and A. G. Yodh, Department Of Physics and Astronomy, University of Pennsylvania

In this contribution we study a set of theoretical issues associated with image reconstruction using near-field diffraction tomography. In order to obtain quality images, for example, one applies spectral filters to the data at several levels of the image processing (i.e. filters with respect to spatial frequencies in the reconstructions). Well defined rules do not exist for choosing these filter functions; in fact different filter functions introduce uncontrolled systematic errors into the images. Additionally, the images are dramatically improved when the experimenter has knowledge of the approximate depth of the optical heterogeneity. Object depth determination is generally difficult unless one has other means to obtain this information such as multiple optical views of the same sample or image segmentation from other types of diagnostics.

We introduce two filtering methods for near-field diffuse light diffraction tomography based on the angular spectrum representation. We then combine these filtering techniques with a new method to find the approximate depth of the image heterogeneities. Taken together these ideas improve the fidelity of our projection image reconstructions, provide an interesting three dimensional rendering of the reconstructed volume, and enable us to identify and classify image artifacts that need to be controlled better for tissue applications. The analysis is accomplished using data derived from numerical finite difference simulations with added noise. 


\title{
ADVANCES IN OPTICS \\ FOR BIOTECHNOLOGY, MEDICINE AND SURGERY
}

\section{DETECTOR AND CALIBRATION STUDIES FOR UV LASER INDUCED FLUORESCENCE DETECTION OF TRACE CHEMICAL CONCENTRATIONS IN AQUEOUS SOLUTIONS}

\author{
Dennis K. Killinger, University of South Florida \\ Department of Physics, Tampa, FLorida, 33620, USA \\ T: 813-974-3995, F: 813-974-2635, Killinge@chuma.cas.usf.edu \\ Vasanthi Sivaprakasam, University of South Florida
}

A tunable ( $240 \mathrm{~nm}$ to $340 \mathrm{~nm}$ ) UV Laser Induced Fluorescence sensor system has been developed and characterized for the detection of trace species in water. The complete emission spectrum $(250 \mathrm{~nm}$ to $600 \mathrm{~nm}$ ) was obtained from several compounds and provided assessment of the technique for Excitation Emission Matrix, EEM, spectroscopy. The system has been used for the detection of sub $\mathrm{ppb}$ organic and plastic compounds leached into pure water by the immersion of supposedly inert plastic tubing in water for short periods of time. In order to optimize the detection system, the excitation laser, spectrometer and CCD detector, different detectors (PMT versus CCD), and collection optics geometry were studied experimentally. It was found, for the first time to our knowledge, that the standard calibration proceedure of using the Raman (water) to Fluoresence ratio of a standard fluorescence compound, Quinine Sulfate, was not valid under certain laser beam excitation and collection optics cases. The experimental results were shown to agree with theoretical predictions that take into account the excitation polarization,collection optics vectors, and integrated solid-angle effects on the CCD pixels. 


\section{ADVANCES IN OPTICS \\ FOR BIOTECHNOLOGY, MEDICINE AND SURGERY \\ COMPACT MEDICAL FLUOROSENSOR FOR MINIMALLY INVASIVE TISSUE CHARACTERISATION}

Stefan Andersson-Engels, Department of Physics, Lund Institute of Technology

P.O. Box 118, SE-221 00 Lund, Sweden

T: +46-46-2223119, F: +46-46-2224250, stefan.andersson-engels@fysik.lth.se

Claes af Klinteberg, Department of Physics, Lund Institute of Technology

Markus Andreasson, Department of Physics, Lund Institute of Technology

Ola Sandstrơm, Department of Physics, Lund Institute of Technology

Sune Svanberg, Department of Physics, Lund Institute of Technology

A compact point-measuring fluorosensor fully adapted to clinical studies is described. The developed system is flexible and it is thus possible to adapt the analysis to different clinical applications. This has been realised by employing differences in fluorescence excitation as well as emission and lifetime. The system has been designed to be compact and is operated through a user interface specially designed for this application. The system is fully computer controlled, enabling short recording times. 


\section{ADVANCES IN OPTICS \\ FOR BIOTECHNOLOGY, MEDICINE AND SURGERY}

\section{NIR SPECTROSCOPIC STUDIES OF FETAL BRAIN IN-UTERO : EVALUATION OF SENSITIVITY AND ACCURACY OF THE SYSTEM TO THE FETAL CEREBRAL BLOOD SATURATION}

Gargi Vishnoi, School of Medicine, University of Pennsylvania Johnson Research Foundation, D 501, Richards Bldg., 37th \& Hamilton Walk, Philadelphia, PA, 19104-6089, USA

T: 1-215-898-3296, F:1-215-898-1806, gargi@mail.med.upenn.edu Andreas H. Hielscher, Department of Pathology, State University of New York

Nirmala Ramanujam, School of Medicine, University of Pennsylvania Shoko Nioka, School of Medicine, University of Pennsylvania

Britton Chance, School of Medicine, University of Pennsylvania

We performed numerical simulations, experiments on tissue phantoms, and clinical studies to investigate near-infrared (NIR) photon migration through fetal head in-utero. Computer simulations were performed using time-independent, finite-difference, radiative-transport equation. Simulations were used to determine photon distribution within the phantom and optimize source-detector (S-D) configuration. These simulations were validated against NIR measurements from in-utero tissue phantoms using continuous-wave spectrometer and compared to clinical trans-abdominal measurements. A comparison between theoretical, experimental and clinical investigations indicated that 1) the fetal head in-utero represented by rectangular geometry closely reflects the boundary conditions between fetal head and maternal tissue; 2) maximum sensitivity can be achieved when the S-D pair is placed on the maternal abdomen such that the source lies directly above fetal head; 3) S-D separation of $7 \mathrm{~cm}$ is optimal.

Subsequently, we employed a frequency domain spectrometer with $7 \mathrm{~cm} \mathrm{S-D} \mathrm{separation} \mathrm{to} \mathrm{study}$ the sensitivity of trans-abdominal measurements to changes in absorption coefficient $\left(\mu_{\Omega}\right)$ of the fetal head. For this study, we used a tissue phantom consisting of a maternal layer, an amniotic fluid sac and a fetal head with appropriate absorption and scattering coefficients. Phase and amplitude measurements were made as a function of maternal tissue thickness; and as a function of change in $\mu_{\mathrm{a}}$ of the fetal head for a fixed maternal tissue thickness. $\mu_{\mathrm{z}}$ was calculated using diffusion equation for semi-infinite geometry. Evaluation of the accuracy of quantifying fetal head $\mu_{2}$ as a function of maternal tissue thickness indicates that it deviates from 15 to $88 \%$ as maternal tissue thickness ranges from 1 to $4 \mathrm{~cm}$. Further, evaluation of the sensitivity to a change in the $\mu_{2}$ of fetal head at a maternal tissue thickness of $3 \mathrm{~cm}$ suggests that for a change in $\mu_{2}$ of $0.01 \mathrm{~cm}^{-1}$ (corresponding to a $10 \%$ change in blood saturation for physiological range) results in an overall change of $0.002 \mathrm{~cm}^{-1}$ experimentally with the standard deviation of $0.0005 \mathrm{~cm}^{-1}$. 


\title{
ADVANCES IN OPTICS \\ FOR BIOTECHNOLOGY, MEDICINE AND SURGERY
}

\section{POLARIZED LIGHT SCATTERING SPECTROSCOPY FOR DIAGNOSIS OF PRECANCER}

\author{
Rajan S Gurjar, Massachusetts Institute of Technology \\ George R Harrison Spectroscopy Laboratory, 6A-230, Vassar Street, Cambridge, Massachusetts, \\ MA-02139, USA \\ T: 617-258-7831,F: 617-253-4513, rajn@mit.edu \\ L T Perelman, Vadim Backman, Irving Itzkan, R R Dasari and M S Feld, Massachusetts Institute of \\ Technology, Cambridge \\ Kamran Badizadegan, Children's Hospital, Boston
}

This poster will present a new light scattering technique based on polarized reflection spectroscopy as a diagnostic tool in pathological examination. Most cancers originate in the cells lining the epithelial surfaces of the body. These cells undergo well known microscopic changes in dysplasia, the condition that is the precursor to cancer. Although these cells do not fluoresce or absorb in the visible, their scattering properties change dramatically, and such changes can provide a spectroscopic indication for dysplasia. Polarization as an additional degree of freedom can be used to enhance the scattering features from the cells. Scattering from a monolayer of cells retains the input polarization of the light, while diffusive scattering from underlying tissue destroys this polarization. We use this fact to remove the large diffuse background and obtain spectroscopic signatures from the cells residing in the epithelium. From these measurements, accurate quantitative estimations of nuclear size and refractive index are obtained. This new technique was first demonstrated in physical models employing polystyrene spheres as scatterers, and then applied to monolayers of cancerous and normal colon cells and ex vivo tissue samples. The experiments clearly differentiated the normal from the cancerous cells. The distribution of the nuclear sizes acquired using this technique are in good agreement with the distribution obtained using microscopic examination of the cell population. Additionaly differences in the relative refractive index of the normal and cancerous cells were observed. Plans for clinical studies using an in vivo system will also be presented. 


\section{ADVANCES IN OPTICS \\ FOR BIOTECHNOLOGY, MEDICINE AND SURGERY}

\section{DYNAMIC TOMOGRAPHIC IMAGING OF VASCULAR REPERFUSION}

Christoph H. Schmitz SUNY Health Science Center at Brooklyn

Box 25, 450 Clarkson Ave., Brooklyn, NY, 11203, U.S.A.

T: (718) 270-2832, F: (718) 270-3313, cschmitz@netmail.hscbklyn.edu

Harry L. Graber, SUNY Health Science Center at Brooklyn

Randall L. Barbour, SUNY Health Science Center at Brooklyn

We have constructed a fast dual wavelength optical tomographic imager, which is capable of evaluating a range of anatomical sites. Current speeds are $4 \mathrm{~Hz}$ with a single source and with modification will operate at $10 \mathrm{~Hz}$ for multi-source illumination. In one series of experiments we have performed optical measurements on the forearm of a volunteer before, during, and after release of a pressure cuff. All during this time 6-source, 18 detector measurements were collected yielding a total of 120 images for each wavelength $(780,810 \mathrm{~nm})$ with a temporal resolution of $0.5 \mathrm{sec}$ per wavelength.

The computed images were then evaluated using time series analysis methods from which were derived two complementary composite images. One was obtained by identifying in each pixel that frequency in the Fourier spectrum having the greatest amplitude and the other by computing an interpixel cross-correlation map. Comparison of the images showed that coincident with a low frequency region located in the central aspects of the forearm was a region having similar boundaries and a high positive correlation, indicating that all pixels within this region are simultaneously experiencing a low frequency change (i.e., reperfusion).

To the best of our knowledge this is the first demonstration of real-time monitoring, in a crosssectional view, of a reperfusion event involving the microvasculature for a large tissue structure. 


\title{
ADVANCES IN OPTICS \\ FOR BIOTECHNOLOGY, MEDICINE AND SURGERY
}

\section{POLARIZED, WAVELENGTH DEPENDENT ELASTIC-SCATTER SPECTRA}

\author{
Judith R. Mourant, Los Alamos National Laboratory \\ MS E535, Los Alamos, NM, 87545, US \\ T: (505) 665-1190, F: (505) 665-4637, jmourant@lanl.gov \\ Tamara M. Johnson, Los Alamos National Laboratory
}

Wavelength-dependent, polarized, elastic-scatter spectra of tissue phantoms and in vitro tissue have been measured. Both images and fiber optic based measurements were obtained. The newly designed fiber optic probe should be relatively easy to implement in vivo and only collects light that is linearly polarized in the same direction as the illumination. There are four collection fibers arranged symmetricaly around the delivery fiber. A polarization ratio is defined as the ratio of light collected by fibers at 90 and 0 degrees, where the delivery fiber is at the origin and 0 degrees is defined by the oscillation direction of the electric field passed by the polarizer. The wavelength dependence of the polarization ratio can be measured in an absolute manner by taking advantage of the fact that the polarizer did not polarize light with wavelengths greater than $900 \mathrm{~nm}$. This polarization ratio can provide better sensitivity to small changes in polarized light than unpolarized measurements and can be used to distinguish very similar suspensions of polystyrene spheres containing slightly different ratios of small and large spheres. In addition, it is found that the polarization ratio is very different for liver and chicken tissue. A very simple model based on the polarization properties of single scattering events of spheres reproduces the experimentally determined polarization ratio reasonably well. Based on this model it is inferred that the probability of scattering events at medium and medium/large angles controls the amount of light that is collected with its polarization properties preserved. Since scattering from biological cells at these angles is believed to be due to scattering from internal structures of the cells, the polarization ratio is expected to be sensitive to changes in the internal morphology of biological cells. 


\title{
ADVANCES IN OPTICS \\ FOR BIOTECHNOLOGY, MEDICINE AND SURGERY
}

\section{TWO-PHOTON EXCITED IMAGING OF TISSUE REMODELING}

\author{
Vincent P. Wallace, Beckman Laser Institute, UC Irvine \\ 1002 Health Science Road, Irvine, CA, 92612, USA \\ T: (949) 824 4713, F: (949) 824 8413, vwallace@bli.uci.edu \\ Mariah L. Coleno, \\ Chung-Ho Sun, \\ Bruce J. Tromberg, Beckman Laser Institute
}

Two-photon laser scanning microscopy (TPM) is a non-invasive biological imaging technique that can be used to selectively image cellular activity, photosensitizer localization, and the extracellular matrix (ECM) within highly scattering tissues at depths of -250 microns with submicron resolution. Cells of the monocyte/macrophage lineage migrate through the ECM and mediate the wound healing immune response. Macrophage depletion impairs wound healing, while overexpression of macrophage products (cytokines) leads to overproduction of collagen thus producing chronic inflammatory states, which can lead to excessive tissue scarring. The objective of this study was to develop a model system for understanding the impact of perturbations, such as PDT, on cellular and extracellular matrix remodeling in biological tissues (skin, lung epithelium and cornea). An artificial tissue model (RAFT) composed of collagen, embedded fibroblasts, and macrophage cells has been developed for this purpose. TPM is used to monitor extracellular matrix remodeling following addition of growth factors, light stimulation and PDT by imaging the autofluorescence of collagen bundles. By varying parameters, we can control tissue contraction through fibroblast activity and collagen formation. Our results show that selective uptake of photosensitizers by specific cellular components in the matrix can be imaged by TPM. In addition, we are able to visualize wound contraction the remodeling ptocess following stimulation of fibroblast activity. This shows that TPM is a useful tool vital to understanding the underlying mechanisms regulating wound healing. 


\title{
ADVANCES IN OPTICS \\ FOR BIOTECHNOLOGY, MEDICINE AND SURGERY
}

\section{MONTE CARLO SIMULATIONS OF POLARIZED LIGHT PROPAGATION IN MICROSPHERE SUSPENSIONS}

\author{
Duncan Maitland, Lawrence Livermore National Laboratory \\ L-399, P.0. Box 808, Livermore, CA, 94551, US \\ T: 925-423-6697, F: 925-424-2778, dmaitland@llnl.gov \\ Vanitha Sankaran, Lawrence Livermore National Laboratory \\ George Zimmerman, Lawrence Livermore National Laboratory \\ Richard London, Lawrence Livermore National Laboratory
}

A numerical simulation code is used to investigate the basic physics of polarized light propagation in scattering media. The photon propagation code used in these investigations is a part of LATIS, which simulates laser-tissue interactions. A 3D Monte Carlo propagation model has been modified to include polarization. Each photon carries a Stokes vector description of its polarization state. A particular photon's scattered polarization state is a function of its incident polarization state and an electromagnetic scattering cross-section in the form of a Mueller matrix. The Mueller matrices are a function of incident and scattered photon angles. Analytic Mie scattering cross-sections were used to generate the Mueller matrix particle descriptions for the simulations. The results are in excellent agreement with transmission experiments obtained in our laboratory for dilute suspensions of polystyrene microspheres. The validated simulation code was used to investigate basic science and instrumentation issues pertinent to image objects embedded in scattering media. The results presented include the effects of collection aperture, collection angle, incident polarization state, polarization state as a function of the number of scattering events and simulations of imaging embedded objects.

This work was performed under the auspices of the US. Department of Energy by the Lawrence Livermore National Laboratory under Contract W-7405-ENG-48. 
ADVANCES IN OPTICS

FOR BIOTECHNOLOGY, MEDICINE AND SURGERY

\section{MEASUREMENTS OF THE OPTICAL TRAP STIFFNESS: TWO-PHOTON FLUORESCENCE TO THE RESCUE!}

Tatiana B. Krasieva, Ph.D., Beckman Laser Institute, University of California, Irvine 1002 Health Sciences Road, East, Irvine, Ca, 92612, U.S.A.

T: 949 824-3664, F: 949 824-8413, tkrasiev@bli.uci.edu

Andrew K. Dunn, Ph.D., Joon S. You,

Bruce J. Tromberg, Ph.D., Beckman Laser Institute, University of California, Irvine

Optical tweezers utilize the radiation pressure from a single near $\mathbb{R}$ laser beam to hold and manipulate microscopic objects such as cells and subcellular structures. The ability to calculate trapping forces is commonly applied to the study of molecular motors (e.g., kinesin, actomyosin) which are key players in the immune response, cellular motility and development. Optical trapping has also been utilized in studies of elastic properties of cell membranes and DNA macromolecules.

Presently, no general theory exists for computing the trapping force on an arbitrary object within an optical trap. Therefore, these forces must be measured empirically which is a difficult task given the small size of the objects and the complex nature of the laser beam. Current accurate force calibration methods such as the measurement of particle displacement within an optical trap requires highly sophisticated software solutions (e.g., special tracking imaging stations) or very demanding optical hardware (e.g., interferometry).

The proposed method utilizes the same trapping beam to hold a fluorophore-coated bead while simultaneously exciting two-photon fluorescence in the small volume near the waist of a trap. This combination provides an easy way to measure the distance between the geometrical center of the sphere and the position of the trapping beam. In our experiments we used 1,2 and $6 \mu \mathrm{m}$ polystyrene beads coated with YG dye (Polyscienses, Inc) and $2 \mu \mathrm{m} \mathrm{IgG-YG} \mathrm{coated} \mathrm{beads.} \mathrm{It}$ enabled us to measure the stiffness of an optical trap over $0.5-10 \mathrm{pN} / \mathrm{nm}$ range for $820 \mathrm{~nm}$ laser beam delivered through a $100 \times$ (n.a. 1.3) $\mathrm{Ph} 3$ Neofluar objective. 


\title{
ADVANCES IN OPTICS \\ FOR BIOTECHNOLOGY, MEDICINE AND SURGERY
}

\section{MIT LASER BIOMEDICAL RESEARCH CENTER}

\author{
Lev T. Perelman, Massachusetts Institute of Technology \\ 77 Massachusetts Avenue, Cambridge, Massachusetts, 02139, USA \\ T: 617-253-4520, F: 617-253-4513, Itperel@mit.edu \\ Qingguo Zhang, \\ Irving Itzkan, \\ Ramachandra R. Dasari, \\ Michael S. Feld,
}

The overall goal of the MIT Laser Biomedical Research Center (LBRC) is to develop new technology and advance research in the field of laser biomedicine. LBRC activities fulfill both research and educational objectives. Research activities can be divided into core, collaborative and outside projects. Core researchers are using the LBRC's unique laser resources to develop spectral methods for diagnosing disease and measuring concentrations of chemical and morphological constituents of biological tissues. They are devising novel, spectroscopy-based techniques for endoscopic imaging, optical tomography and medical instrumentation. And they are developing a fundamental understanding of tissue ablation, and using lasers and spectroscopy to study biophysical and biochemical properties of molecules, cells and tissues. Collaborative projects enable non-core researchers to interact with the Center's staff to pursue areas of common interest which further the LBRC's research objectives. Many of these collaborators are. physicians working at the interface between basic research and its clinical implementation. Examples include the development Raman histochemistry and histopathology as well as endoscopic-based techniques employing reflected light and fluorescence to detect and quantify dysplasia in the mucosal surfaces of oral cavity, esophagus, colon and bladder and various other organs. LBRC facilities are also made available to qualified outside investigators to pursue independent research projects. For example, outside researchers have employed Raman spectroscopy to probe structural modifications in the protein $\mathrm{g}$ II-crystallin and its role in lens aging and cataract formation, and a wide range of other topics requiring sophisticated laser equipment and technology. These exciting projects illustrate the impact lasers are making on advancing the frontiers of medicine. 


\section{ADVANCES IN OPTICS}

FOR BIOTECHNOLOGY, MEDICINE AND SURGERY

\section{FUNCTIONAL CEREBRAL ACTIVITY MEASUREMENT BY DIFFUSING LIGHT}

Cecil Cheung, Dept. of Physics and Astronomy, University of Pennsylvania

209 S. 33rd Street, Philadelphia, PA, 19104, usa

T: 215-5733463, F: 215-5736391, cheung@dept.physics.upenn.edu

J. P. Culver, Dept. of Physics and Astronomy, University of Pennsylvania

K. Takahashi, Cerebrovascular Research Center, Dept. of Neurology, University of Pennsylvania

School of Medicine

J. H. Greenberg, Cerebrovascular Research Center, Dept. of Neurology, University of

Pennsylvania School of Medicine

A. G. Yodh, Dept. of Physics and Astronomy, University of Pennsylvania

We develop an optical instrument that measures the functional changes on the cerebral blood flow, blood volume, and hemoglobin oxygenation saturation. The measurements are done through an intact skull in a non-invasive and non-contact way. Experimental results on rat brains will be presented.

The optical probe has a number of fiber optics arranged in a two-dimensional array. Some of the fibers are light sources, while the others collect the backscattered light from the animal. The arrangement enables us to reconstruct regional images of the cerebral cortex. The instrument has separate electronics to perform a diffuse photon density wave (DPDW) measurement at two optical wavelengths (777nm and $830 \mathrm{~nm}$ ), and a diffusing-wave correlation spectroscopy (DWS) measurement at $800 \mathrm{~nm}$. DPDW measures both the scattering and absorption coefficients. DWS measures the average flow speed. Changes in the absorption coefficients at the two optical wavelengths upon a stimulation give the functional changes in the cerebral blood volume and hemoglobin saturation. Changes in the cerebral blood flow is directly measured by DWS.

Experiments on rats show that our methods can detect changes in the blood flow, blood volume, and hemoglobin saturation upon a whole brain activation such as hypercapnia, as well as a regional activation such as electrical paw stimulation.

Our methods can measure blood flow in deeper tissue volumes than laser Doppler flowmetry can achieve. Moreover, by co-registering the blood flow with the hemoglobin saturation, we may estimate the local oxygen metabolic rate and hence infer the regional brain activity. 


\section{ADVANCES IN OPTICS}

FOR BIOTECHNOLOGY, MEDICINE AND SURGERY

\section{SPECTRAL ANALYSIS OF TWO PHOTON EXCITED FRET OF GFP FUSION PROTEINS}

Vickie J. LaMorte, Ph.D., Beckman Laser Institute, University of California, Irvine

1002 Health Sciences Road East, Irvine, CA, 92612, USA

T: 949-824-3513, F: 949-824-8413, lamorte@bli.uci.edu

Andrew Dunn, Ph.D., Mariah L. Coleno,

Vincent Wallace, Ph.D., Tatiana B. Krasieva, Ph.D.,

Gopi K. Manthripragada, Bruce J. Tromberg, Ph.D.

Understanding the function of a protein by following its dynamic interplay with other proteins in a living cell can contribute fundamentally to the overall cellular process or disease in which it participates. The principles of FRET or fluorescence resonance energy transfer serve as the basis for the development of new methodology which utilize mutants of the green fluorescent protein (GFP). A major drawback in utilizing FRET as a means of determining protein interaction (less than $0.01 \mu \mathrm{m}$ ) has been the overlap in spectra between the donor and acceptor GFP fluorophores. To circumvent this issue, we have generated spectral data of the FRET pairs expressed in living cells. Thus with spectral data the energy transfer to the acceptor and its subsequent emission is easily discerned from that of the donor. To further examine submicron areas within the living cell for potential protein pairing or FRET, we utilized a Ti:Sapphire laser at $835 \mathrm{~nm}$ focused to a micron diameter spot size for two photon excitation of the donor mutant GFP and obtained spectral data. These data provide an exciting new twist to utilizing FRET as a means of : following the dynamics of proteins at the subcellular level. This work was funded by NII/NCRR (P-41-RR01192), AHA (9930055N), and ACS (IRG98-279-01). 


\title{
ADVANCES IN OPTICS \\ FOR BIOTECHNOLOGY, MEDICINE AND SURGERY
}

\section{NEAR-INFRARED SPECTROSCOPY TO DLAGNOSE ALZHEIMER'S DISEASE}

\author{
Eugene B. Hanlon, MIT \\ 77 Massachusetts Ave. 6-014, Cambridge, MA, 02139, USA \\ T: 617253 5077, F: 617253 4513, ebhanlon@mit.edu \\ Neil W. Kowall, Boston University School of Medicine \\ Irving Itzkan, Massachusetts Institute of Technology \\ Ramachandra R. Dasari, Massachusetts Institute of Technology \\ Michael S. Feld; Massachusetts Institute of Technology
}

\begin{abstract}
The purpose of this study was to investigate whether near-infrared fluorescence spectroscopy could be used to detect Alzheimer's disease (AD) by brain tissue autofluorescence. Unfixed temporal cortex specimens from $A D$ cases and age-matched, non- $A D$ controls were frozen at autopsy and then thawed just prior to spectral measurement. Spectra of intrinsic tissue fluorescence induced by $647 \mathrm{~nm}$ light were recorded from 650 to $850 \mathrm{~nm}$. We used principal component analysis of the tissue spectra from $17 \mathrm{AD}$ cases and 5 non-AD control cases in a calibration study to establish a diagnostic algorithm based on the first two principal component scores. Retrospectively applied to the calibration set, the algorithm correctly classified 23 of 24 specimens. In a prospective study, 17 of 19 validation specimens from 5 AD brains and 2 nonAD control brains were correctly diagnosed. Logistic regression applied to the principal component scores of the calibration set yielded a model using three scores that classified each spectrum from each specimen with $100 \%$ accuracy. The same logistic model, applied : prospectively to the validation set, also yielded $100 \%$ accuracy in classifying all 19 validation set specimens. Both the excitation light used and the measured brain tissue autofluorescence are at near-infrared wavelengths that can propagate through skull and overlying tissue. Therefore, this is the first demonstration of an optical spectroscopic technique that carries direct molecular level information about tissue that also has the potential to be applied to the non-invasive diagnosis of Alzheimer's disease in living patients.
\end{abstract}




\title{
ADVANCES IN OPTICS \\ FOR BIOTECHNOLOGY, MEDICINE AND SURGERY
}

\section{NEAR-INFRARED TOMOGRAPHIC IMAGING OF BREAST LESIONS IN VIVO}

\author{
Brian W. Pogue, Dartmouth College \\ Thayer School of Engineering, Hanover, New Hampshire, 03755, USA \\ T: (603) 646-3861, F: (603) 646-3856,pogue@dartmouth.edu \\ Troy O. McBride, Thayer School of Engineering, Dartmouth College \\ Steven P. Poplack, Dept. of Radiology, Dartmouth-Hitchcock Medical Center \\ Ulf L. Osterberg, Thayer School of Engineering, Dartmouth College \\ Keith D. Paulsen, Thayer School of Engineering, Dartmouth College
}

A tomographic system for imaging hemoglobin concentration in tissue has been developed and tested in vivo to image human breast tumors. The system uses diffuse near-infrared intensitymodulated light measurements together with a model-based iterative reconstruction algorithm to achieve the first noninvasive apparatus to recover quantitatively accurate tomographic images of hemoglobin concentration in vivo. To demonstrate the capability of the system, images have been obtained from tissue-simulating media and from the breast tissue of patients with tumors. The potential of this system for medical diagnosis is currently being evaluated in preliminary clinical trials, which have included 14 patients/volunteers to date. Initial studies indicate that hemoglobin concentration is 2-3 times increased in tumor tissue, as compared to the normal variation of breast tissues between patients. The optimization of the hardware and software for the system continues to evolve, and some major improvements to the image quality and accuracy have been obtained. This new type of model-based image reconstruction must be carefully calibrated in tissue- simulating phantoms, but once calibrated can provide a powerful imaging tool for quantiation of hemoglobin concentration and oxygen saturation. 
Endovascular Photodynamic Therapy to prevent Intimal Hyperplasia after Vascular Interventions.

E.E.E.Gabeler MD, R.van Hillegersberg PhD MD, W.Sluiter PhD, R.G.van Eps MD, H.van UrkPhD MD

\section{Background:}

Restenosis is a notorious complication with a high incidence after vascular interventions, which requires frequent re-interventions. Major determinants in the development of restenosis are intimal hyperplasia and vascular remodelling. Recently, the use of photodynamic therapy (PDT) to vascular cell proliferation, which comprises the light activation of photosensitizing drugs to generate cytotoxic mediators, has previously been described, but fundamental questions need to be clarified before the application of this treatment modality in humans. 5-Amino levulinic acid induced protoporphyrin $\mathrm{XX}$, a naturally occuring porphyrin precursor and its fluorescent product, has succesfully been applied as a method of sensitization for PDT. In the present study we searched for the optimal conditions of effective endovascular PDT in a rat model of intimal hyperplasia.

Objectives:

To determine the intimal hyperplasia characteristics after balloon induced injury of the artery and the pharmacokinetics of the photosensitizer.

Materials and methods:

Intimal Hyperplasia (IH): healthy male Wistar rats were generally anaesthetised and underwent a standard balloon angioplasty by intraluminal passage with a Fogarty $2 \mathrm{~F}$ catheter of the carotid artery and aorta. These rats were killed after $1,2,3,4$ and 16 weeks, respectively. The arteries were perfusion-fixed in vivo and sections were microscopically assessed. Digital image analysis was applied for calculating the $\mathbf{I H}$ (area in $\mathrm{mm} 2$ ) and the $\mathbf{I H} /$ media ratio.

Photosensibilisation: During general anaesthesia, ALA (200mg/kg) was injected intravenously in healthy rats. Serum samples and arterial specimens for a fluorometric enzyme assay measurement of ALA and protoporphyrin IX(PPD) were taken after 1,2,3,6 and 12 hours, respectively.

Statistics: The ANOVA and multiple comparison analysis according Bon Ferroni were used. Results:We found that (re)stenosis, expressed as the IH surface in mm2 and as the IH/media ratio, is maximal after 2 weeks in the carotid artery and after 4 weeks in the abdominal aorta. After administration of ALA its concentration rose to a maximum after 1 hour in serum (4.48 umol/ml) and in arterial homogenate $(343 \mathrm{pmol} / \mathrm{mg})$. No ALA could be detected after 6 hours in serum, but remained demonstrable in the homogenate.

The peak concentration of the fluorescent product PP IX was detected after 3 hours for both samples.

Conclusion:

The results of our study showed that the rate of intimal hyperplasia development depends on artery type.

Since the highest ALA concentration is measured after 1 hour, but the highest PP IX concentration is measured after 3 hours, it seems likely to treat the vessels of interest at 3 hours. 



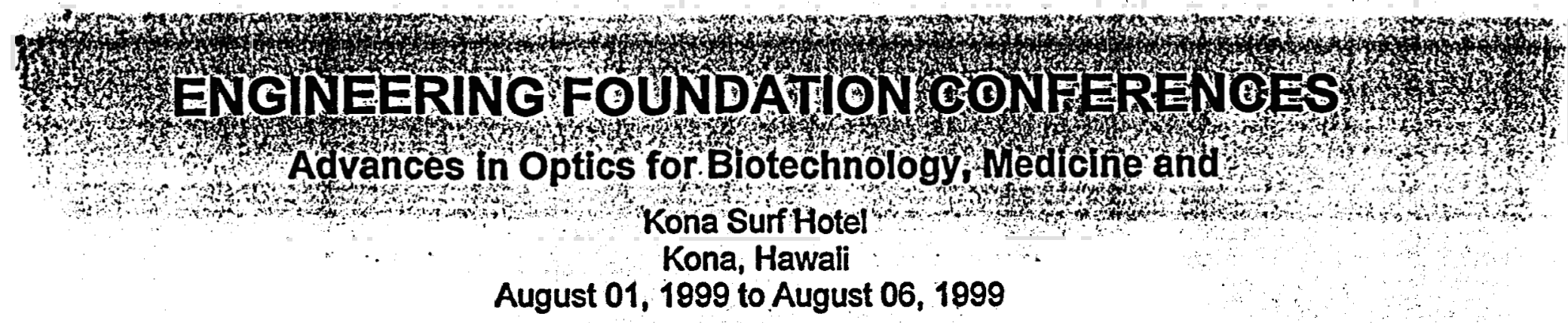

PARTICIPANTS LIST

A'AMAR, OUSAMA

Graduate Student

Los Alamos National Laboratory

MS E535

CST-4 Bioscience \& Biotech.

- Los Alamos, NM 87545

Tel: 505-665-1190

Fax: 505-665-4637

\section{ARNOLD, MARKA.}

Professor

University of lowa

Department of Chemistry

230 lowa Advanced Tech. Labs.

lowa City, IA 52242

Tel: 319-335-1368

Fax: 319-335-1115

E-mail: mark-arnold@uiowa.edu

BARGO, PAULO R.

Graduate Student

Oregon Graduate Institute

Medical Laser Center

9205 S.W. Bames Road

Portland, OR 97225

Tel: $603-216-6830,60+4$

Fax. 503-216-2422

E-mail: pbargo@ece.ogi.edu

BERGER, ANDREW

University of Califorma

obeckman 1 ase In titute

- 1002 Health Sciunces Road, E.

Inine $0 \mathrm{~A} 92612 \mathrm{y}, \mathrm{W}$,
ANDERSSON-ENGELS, STEFAN

Lund Institute of Technology

Physics Department

P.O. Box 118

S-221 00 Lund, SWEDEN

Tel: $46-46-222-3121$

Fax: $46-46-222-4250$

E-mail: stefan.andersson-engels@fysik.th.se

\section{BAER, THOMAS}

- President/CEO

Arcturus Engineering, Inc.

1220 Terra Bella

Mountain View, CA 94043

- Tel: 650-962-3020

Fax: 650-962-3039

E-mail: tmbaer@arctur.com

- BEAUDRY, PIERRE

Executive Director

Att Advanced Research Tech.

2300 Boulevard Alfred Nobel

V.S.L.

Quebec H4S 2A4, CANADA

Tel: $514-832-0777$

Fax: 514-832-0778

E-mail: pbeaudry@art.ca

BIGIO, IRVING J.

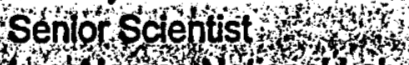
Los Aamos Nationalyo

Biosciences \& Biotechnology

CST 4 NS 535 冈o Fax 949628413 W $1+2$ mal 3)

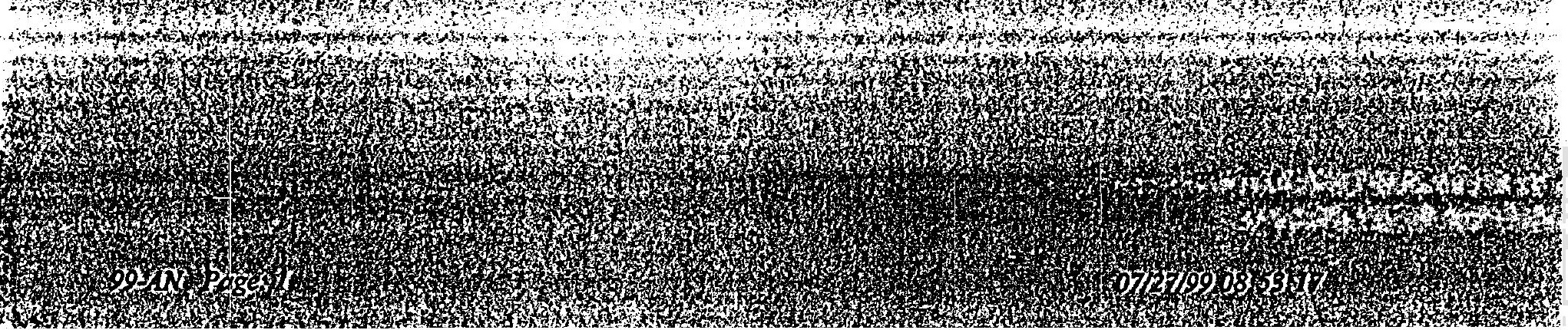


BOAS, DAYMDA.

Assistant Professo

Massachusetts General Hospital

Radiology/NMR Center

CNY Building 149 13th Floor

Charlestown, MA 02129

Tel: 617-724-0130

Fax: 617-726-7422

E-mail: dboas@nmr.mgh.harvard.edu

BOONE, CHARLES $W$.

Program Director

National Institutes of Health

Cancer Chemoprevention Branch

6130 Executive Plaza Blvd.

Bethesda, MD 20892-7322

Tel: 301-594-0421

Fax. 301-594-2943

E-mail:boonec@dcpcepn.nci.nih.gov

\section{BOVA, STEVEN}

Johns Hopkins University

Medical Center

$600 \mathrm{~N}$. Wolfe Street

Baltimore, MD 21287

Tel: 410-614-5957

Fax: 410-614-8736

E-mall: gbov@jhmi.edu

\section{CHALFIN, STEVEN}

University of Texas

Ophthalmology Department

7703 Floyd Curl Drive

San Antonio, TX 78284-6230

Tel: 210-567-8411

Fax: 210-567-8413

E-mail: chalfin@uthscsa.edu
BOWNERROBERTH

Chief, Medical Biophysic

National Institute Health

Biomed Engr 2 Instr. Br.

Building 13, Room 3 N17

Bethesda, MD 20892-5766

Tel: 301-435-1946

Fax: 301-435-5035

E-mail: bonner@helix.nih.gov

BORNHOP, DARRYL J.

Associate Professor

Texas Tech University

Chemistry \& Biochemistry Dept.

Box 41061

Lubbock, TX 79409-1061

Tel: 806-742-3142

Fax. 806-742-1289

E-mail: qzdjb@ttacs.ttu.edu

CARRERO, JENNY

Bio-Optics Scientist

Unilever Research

45 River Road

Edgewater, NJ 07020

Tel: 201-840-2811

Fàx: 201-840-8269

CHAN, KIN FOONG

Graduate Student

University of Texas

ENS 610

Austin, TX 78712

Tel: 512-471-9497

Fax: 512-475-8854

E-mall:kfchan@cowf.cc.utexas.edu

\section{CHEN, ZHONPING}

CHANCE, BRITTON

Professor Emertitus

University of Pentistlvanla

BiochemiBiophys s Department

37th \& Hamilton D 501 R IC

Philadelphia PA 19104.6089

Tel:215-898-4342

Fax 215-8981806

E-mail: chance@ombit tod upenn edu
Professor

University of california

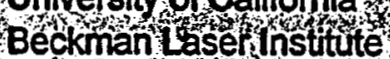

1002 Healt $S$ scences Road E

Invine $\mathrm{CA} 02612$

T. T. $649=824247$

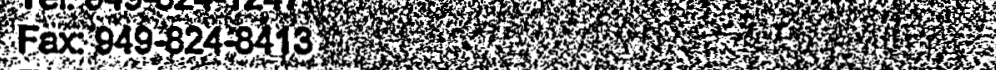

E-mallizchenabilitatedo,

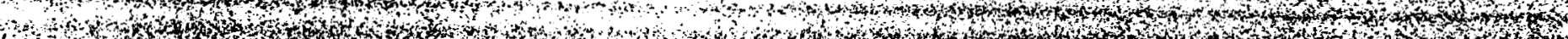

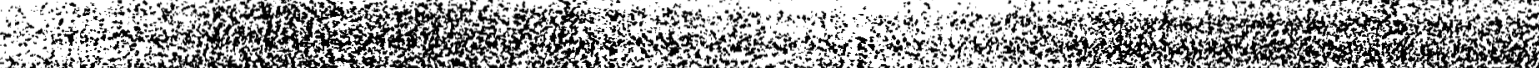


Director, bioengineering:

Pharmacyclics $\mathrm{pos}$

995 East Arques Avenue

Sunnyvale, CA 84086

Tel: 408-774-3357

E-mall: wcheong@pctc.com
Fax: 408-774-0340 University of Pénnsylyanta

Philadelphia, PA 19104

Tel: 215-573-3463

Fax: 215-573-6391

E-mall: cheung@dept.physics.upenn.edu
H

\section{CHOE, REGINE}

Graduate Student

Physics Department

209 South 33rd Street

$\therefore$ Philadelphia, PA 19104

Tel: 215-898-3296

Fax: 215-898-1806

E-mail: rgchoe@mall.sas.upenn.edu

COFFEY, DONALD S.

Professor

Johns Hopkins University

Urology Department

600 North Wolfe Street

Baltimore, MD 21287

Tel: 410-955-2517

COLSTON, BILL

Lawrence Livermore Nat'l. Lab.

7000 East Avenue

Livermore, CA 94550

Tel: 925-423-0375

- Fax. 925-424-2778

E-mail: colston1@ilnl.gov
University of Pennsylvania

Fax: $410-955-0833$

CHOI, BERNARD

University of Texas

Biomedical Engineering Program

ENS Bullding, Room 610

Austin, TX 78712-1084

Tel: $512-471-3619$

Fax: 512-475-8854

E-mail: bemiec@mail.utexas.edu

\section{COLENO, MARIAH L.}

Graduate Student

University of California

Beckman Laser Institute

1002 Health Sciences Road, E.

Irvine, CA 92612

Tel: $949-824-4713$

Fax: 949-824-8413

E-mail: mcoleno@bli.uci.edu

CONTAG, CHRISTOPHER H.

Assistant Professor

Stanford University

School of Medicine

300 Pasteur Drive

Stanford, CA $94305-5208$

Tel: 650-723-0707

Fax. 650-498-7723

E-mail: ccontag@cmgm.stanford.edu

DELPY, DAVID T.

CULVER, JOSEPH P.

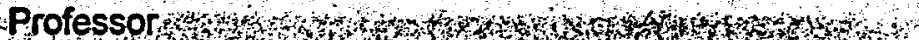

Post Doctoral Fellow

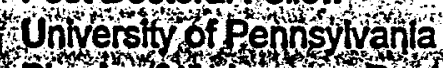

Th physics \& Astronomy Dept 209. South 33 rd Street

YPhiladelpha PA 19130

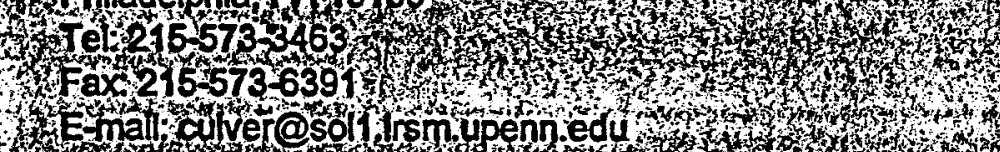

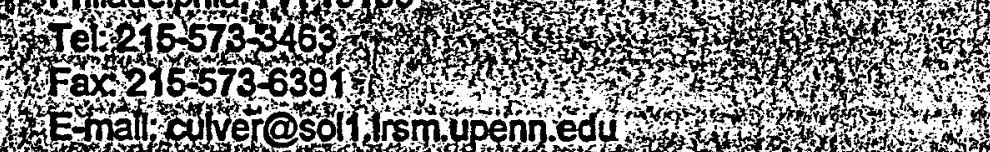

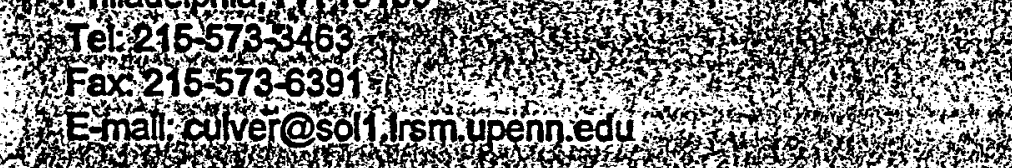

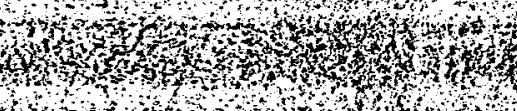

.

列

.




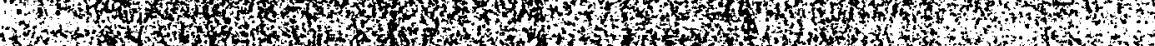

FURLONG, STEVEN\}'

Chief Tectinology Officer

Life Spex, Inc.

11335 NE 122nd Way

Sulte 175

Kirkland, WA 98034

Tel: 425-820-6225

Fax: 425-820-2660

E-mail: furlong@lifespex.com

\section{GEORGAKOUDI, IRENE}

M.I.T.

Spectroscopy Laboratory

77 Massachusetts Avenue

Cambridge, MA 02139

Tel: 617-258-9487

Fax: 617-258-6586

E-mail: ireneg@mitedu

GURJAR, RAJAN S.

Research Fellow

M.I.T.

Spectroscopy Laboratory

Vassar Street, 6A-230

Cambridge, MA 02139

Tel: 617-258-7831

Fax: 617-253-4513

E-mail: rajn@mit.edu

HASAN, TAYYABA

Associate Professor

Harvard Medical School

Massachusetts General Hospital

Dermatology Department

Boston. MA 02114

Tel: 617-726-6996

Fax. 617-726-3192

E-mail: hasan@helix.mgh.harvard.edu

\section{HELL, STEFAN}

Head, High Resolution Optical

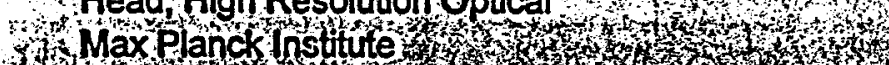

3. Max Planck nstute
Biophysical Chemistry

Am Fassberg 11 th

- 037077 Goettingen GERMANY

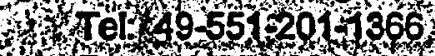

$1 \mathrm{Fax} 495512011085$

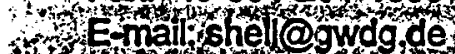

Research Scontist

Rio Grande Medical Tech., Inc 108 Sewall Avenue

Apartment 3

Brookline, MA 02446

Tel: 617-277-7576

Fax: 605-272-4634

E-mail: gardner@rgmt.com

GLICKMAN, RANDOLPH D.

Associate Professor

University of Texas

Ophthalmology Department

7703 Floyd Carl Drive

San Antonio; TX 78284-6230

Tel: $210-567-8420$

Fax: 210-567-8413

E-mail: glickman@uthscsa.edu

HANLON, EUGENE B.

Research Scientist

M.I.T.

77 Massachusetts Avenue, 6-014

Cambridge, MA 02139

Tel: 617-253-5077

Fax: 617-253-4513

E-mail: ebhanlon@mit.edu

HAWRYSZ, DANIEL

Graduate Student

Purdue University

1283 CHME

West Lafayette, IN 47907

Tel: 765-496-2739

Fax: 765-494-0805

E-mall: hawrysżecn.purdue.edi

\section{HERMANN, MARCUS}

Graduate Student Roche Diagnostios $\mathrm{GmbH}$ 166 King Street, $W$

Apt 4

Hamilton Ontario $\mathrm{CANADA}$

Tel. $905-540-4890$ U X

Fax $905-576-6330$

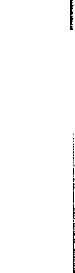

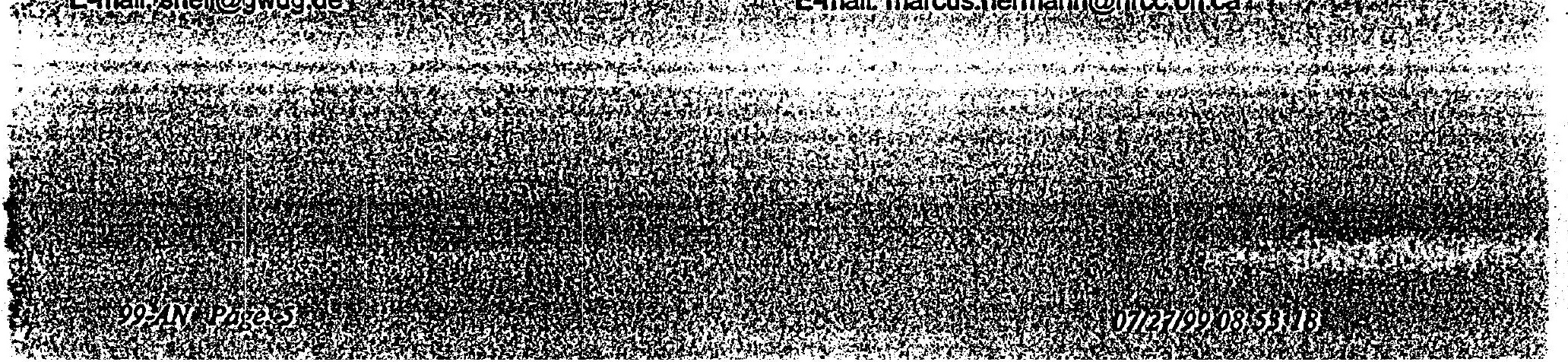


HIELSCHER, ANDREAS H.

Assistant Professor

SUNY Health Science Center

Pathology Department

450 Clarkson Avenue, Box 25

Brooktyn, NY 11203

Tel: 718-270-4562

Fax: 718-270-3313

E-mail: ahielscher@netmail.hscbklyn.edu

HILLENKAMP, FRANZ

Professor

Universitat Munster

Institute fur Med. Physik

Robert Koch Str. 31

D-48149 Munster, GERMANY

Tel: $49-251-835-5103$

Fax: 49-251-835-5121

E-mail: hillenk@uni-muenster.de

KEISER, L. WAYNE

Director, Medical Research

Redwood Regional Medical Group

3555 Round Bam Circle, \#100

Santa Rosa, CA 95403

Tel: 707-528-1050

Fax: 707-525-3874

KILLINGER, DENNIS K.

University of South Florida

Dept of Physios

Tampa, FL 33620

Tel: 813-974-3995

Fax: 813-974-2635

E-mail: killinge@chuma.cas.usf.edu
HiLL, JOHN S.

Miravant Medical Technologies

Medical Research Department

336 Bollay Drive

Santa Barbara, CA 93117

Tel: 805-685-9880

Fax: 805-685-2829

E-mall:.jhill@miravant.com

JACQUES, STEVEN L.

Oregon Medical Laser Center

9205 S.W. Bames Road

Portland, OR 97225

Tel: $503-216-4092$

Fax: 503-216-2422

E-mail: sjacques@ee.ogi.edu
KESSEL, DAVID

Professor

Wayne State University

Pharmacology Department

540 East Canfield Street

Detroit, Ml 48201

Tel: 313-577-1766

Fax: 313-577-6739

E-mail: dhkessel@med.wayne.edu

KIMEL, SOL

Technion

Chemistry Department

Haifa 32000, ISRAEL

Tel: 972-4-829-3946

Fax: 972-4-823-3735

E-mail: chr11sk@tx.technion.ac.il

LAMORTE, VICKIE J.

KRASIEVA, TATIANA B.

Associate Specialist

University of Califoritia

Beckman Laser institute

Assistant Professor.

1002 Health Sciences Road, E.

Irvine, CA 92612

Tel $049-8243664$

Fax 049-824-8413

University of california

Beckman Laser.Institute

1002 Health Sciences Road, E

Inine CA 02612

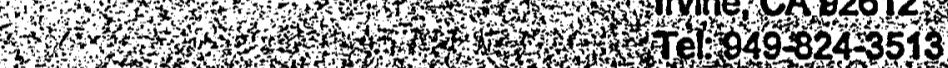

H. WE-mall krasiev@bliuciedu

$\operatorname{Fax} 049-824-8413$

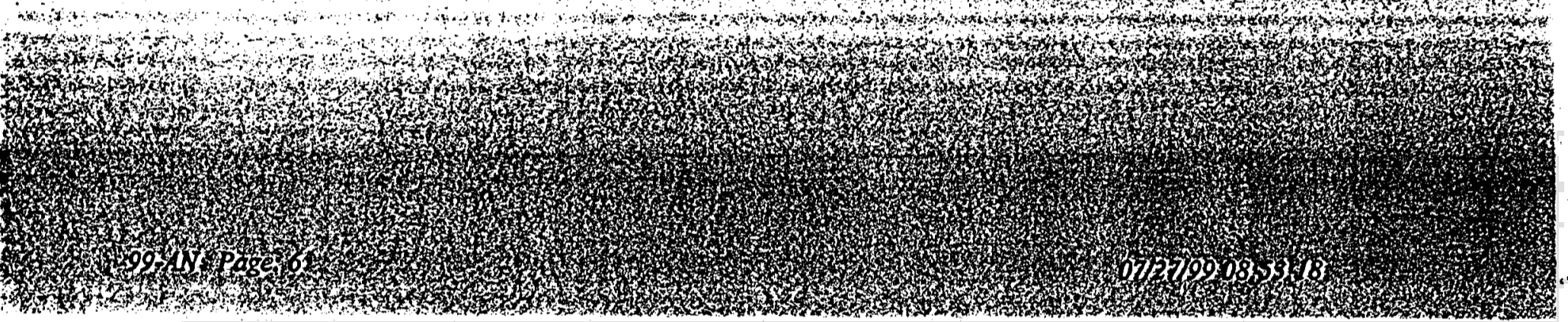




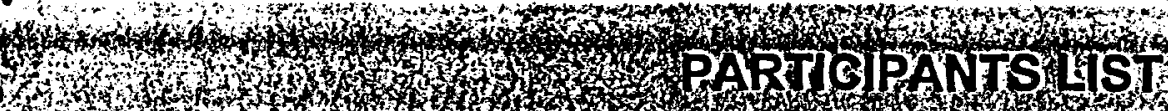

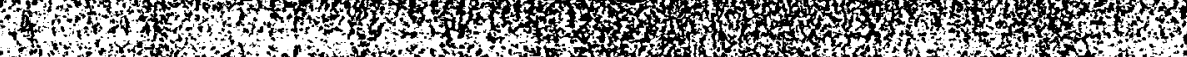

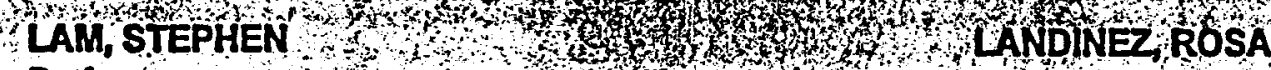

Professor.

Medicine Department

2775 Heather Street.

Vancouver V5Z 3J5, CANADA

Tel: 604-875-4325

Fax: 604-876-5799

E-mail: sclam@interchange.ubc.ca

LOTEM, HAIM

NRCN

74 Shita Street

P.O. Box 402

Omer 84965, ISRAEL

Tel: $972-7-656-7721$

Fax: $972-7-656-8770$

E-mail: lotem@iname.com

MAJARON, BORIS

University of California

Beckman Laser Institute

1002 Health Sciences Road, E.

Irvine, CA 82612-1475

Tel: 949-824-4178

Fax: 949-824-8413

E-mail: majaron@bli.uci.edu

NORDSTROM, ROBERT J.

Vice President, Research

MediSpectra, Inc.

125 Hartwell Avenue

Lexington, MA 02421

Tel: 781-674-0001

Fax: 781-674-0002

E-mail: robeitn@madispectra.com
University of British Columbla

UEF Staff

United Engineering

3 Park Avenue

27th Floor

New York, NY 10016-5902

Tel: 212-591-7836

Fax. 212-591-7441

E-mail: engfnd@aol.com

MAITLAND, DUNCAN J.

Group Leader

Lawrence Livermore Nat'l. Lab.

700 East Avenue

L-339

Livermore, CA 94550

Tel: $925-423-6697$

Fax: 925-424-2778

E-mall: dmaitland@llni.gov

MOURANT, JUDITH R.

Los Alamos National Lab

CST-4, MS E535

P.O. Box 1663

Los Alamos, NM 87545

Tel: 505-665-1190

Fax: 505-665-4637

E-mail: jmourant@lanl.gov

NTZIACHRISTOS, VASILIS

University of Pennsylvania

D501 Richards Bullding

Philadelphla, PA $19104-6089$

Tel: 215-898-4342

Fax. 215-898-1806

E-mall: vasilis@mall.med.upenn.edu

PATTERSON, MICHAEL S.

Head of Medical Physics

Assistant.Professor

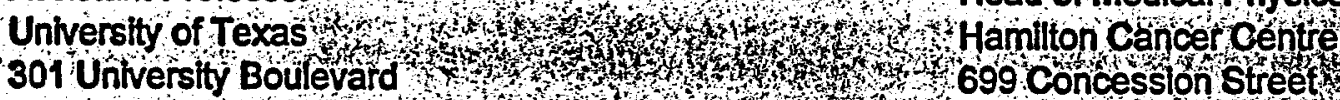

MS 0456

Galveston, TX77555

Trel. $409772-8348$

Ffax 409-772-075

E-mail:aaoraevs@utmb.edu

op.

Hamiltón, Ońtárí LBV $6 C 2,6$ ANADA

Tel: 8053879711 ,

Fax 00555756330

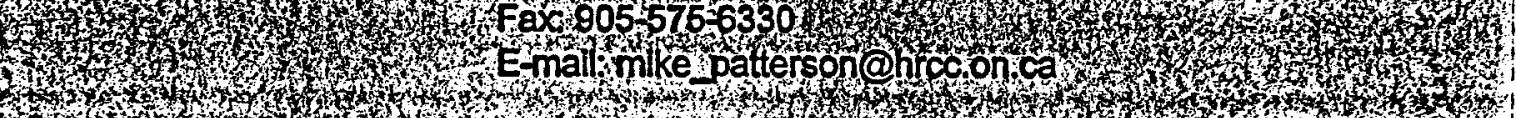
7

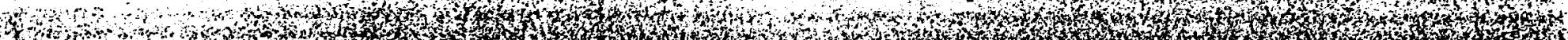

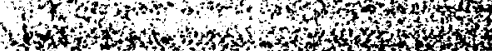

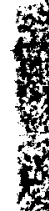


VISUR, STEVENR

Research scientist

Lawrence Livermore Nat"I Lab.

P.O. Box 808, L-399

Livermore, CA 94551

Tel: 825-424-3517

Fax: 925-424-2778

E-mail: visuri@linl.gov

WAYNANT, RONALD W.

Medical Research Officer

Food and Drug Administration

Electro-Optics Branch

M/S HFZ-134 12725 Twinbrook

Rockville, MD 20857

Tel: $301-827-4688$

Fax: 301-827-4677

E-mail: ron@eob.corih.fda.gov

WONG, BRIAN J.

Assistant Professor

University of Califormia

Beckman Laser Institute

1002 health Sciences Road, E.

Irvine, CA 92612

Tel: 949-824-6996

Fax: 949-824-8413

E-mail: bjiwong@bli.uci.edu

YODH, ARJUN G.

Professor

University of Pennsylvania

Physics \& Astronomy Dept.

209 South 33rd Street

Philadelphia, PA 19104-6396

Tel: 215-898-6354

Fax. 215-898-2010

E-mail: yodh@dept.physics.upenn.edu

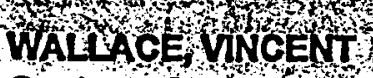

Graduate Student

Beckerman Laser Institute?

1002 Health Sclence Road, East

Irvine, CA 92612

Tel: 849-824-4713

Fax: 849-824-8413

E-mail: vwallace@bli.uci.edu

WILSON, TONY

Professor, Engineering Science

University of Oxford

Engineering Science Dept.

Parks Road

Oxford OX1 3PJ, UNITED KINGDOM

Tel: 44-1865-273-116

Fax: . 44-1865-273-905

E-mail: tony.wilson@eng.ox-ac.uk

WOODBURN, KATHRYN

Pharmacyclics

995 E. Arques Avenue

Sunnyvale, CA 94086

Tel: 408-774-0330

Fax: 408-774-0340

E-mail: kathy@pcyc.com

ZULUAGA, ANDRES F.

Graduate Student

University of Texas

Biomedical Engineering Program

24th \& Speedway Streets

Austin, TX 78705

Tel: 512-471-4703

Fax: 512-475-8854

E-mail: a.f.zuluaga@mail.utexas.edu
6 


\section{THE ENGINEERING FOUNDATION AND FOUNDATION CONFERENCES}

The following is a brief summary from The First 75 Years: A History of the Engineering Foundation by Lance $E$. Metz and Ivan M. Viest.

In 1914, Cleveland manufacturer Ambrose Swasey offered to provide funds for support of engineering research. In response, the United Engineering Society (UES), a public corporation composed of representatives of the societies of electrical, mechanical and mining engineers, established the Engineering Foundation as a department of UES. This new organization was given the power to receive and administer funds from any source for the purpose of supporting "the furtherance of research in science and engineering, or advancement in any other manner of the profession of engineering and the good of mankind."

The Foundation soon began receiving requests for funding various research projects. The first grant was awarded in February 1916 to conduct research on the strength and wearing power of gears. To this day, sponsorship of research projects has continued as one of the principal activities of the Foundation. The Foundation provided financial support to some 400 projects, most of which can be classified as engineering research or engineering-related research.

The first major contribution of the Engineering Foundation to the development of American engineering was the role it played in the establishment of the National Research Council. Created in 1916 by the National Academy of Sciences, at the request of President Wilson for the purpose of engendering cooperation of governmental, educational, industrial and other research agencies in the dual interest of national defense and of scientific and industrial research, the new Council had no tunds to begin th operations. The Engineering Foundation filled the need by financing the NRC during the first year of its existence.

However, the bulk of the Foundation's activities through 1930 can be characterized as sponsorship of engineering research projects. Fatigue of metals, thermal properties of steam, Investigation of arch dams, concrete and reinforced concrete arches, blast furnace slag investigation, dielectric absorption and electric insulation, earth and foundations, barodynamic research, and the effect of temperature on properties of metals are a few engineering research studies of the 45 projects for which financial support was provided by the Foundation during this period. Mental hygiene of industry, Industrial personnel problems, and engineering aptitudes are examples of Foundation-sponsored engineering related studies of this period.

The Fatigue of Metals Project was carried out jointly with the National Research Council. It was the first systematic study of the strength of metals under repeated loading undertaken in the United States. It led to the development of the American Welding Society's welding code that became a basis for the design of machinery, rolling stock, bridges, airplanes, spacecraft, electrical equipment and various other welded devices which were subjected to frequently repeated loads.

The Thermal Properties of Steam Project provided the first authoritative international tables relating steam pressure, temperature and volume in a form readily usable in the design of bollers, engines and other steam appliances. The Arch Dam investigation Involved many investigators and is considered a testing ground for research through cooperative efforts.

The Engineering Foundation began its involvement in efforts to improve engineering education through its support of the Engineers Council for Professional Development, known today as the Accreditation Board for Engineering and Technology. To help alleviate the impact of the Depression on individual engineers, the Engineering Foundation sponsored courses for unemployed engineers. 
Research on the alloys of iron was the major project which involved cooperative research and writing * similar to the activities which were pioneered by the Arch Dam investigation. However, it went a giant step further through its truly national scope and world-wide collection of data. The results were published in a series of 16 books that contained the most encompassing and authoritative information on the subject of steel.

The Welding Research Committee (now Council) was founded in 1935 as an outgrowth of the earlier study of fatigue of metals and was the model for the formation of several research councils during the post World War II period. The WRC successfully promoted the development and use of good welding practices and thus speeded up the acceptance of this basic metal connecting technique.

Between 1946 and 1960 several additional research councils were formed. These independent bodies were formed on the basis of nationwide representation from academic, industrial, and governmental organizations which were interested in the same broad field of engineering. The Structural Stability Research Council, Research Council on Structural Connections, and Reinforced Concrete Council are three such examples. The research councils planned needed research projects, secured the needed financing, selected the research institution, monitored or supervised the conduct of research and channeled the research findings into practical use. The building of record-height buildings such as the World Trade Center, the Sears Tower, the John Hancock Tower, and various more sophisticated structures such as the Assembly building at Cape Canaveral were made possible only because of the expansion of basic knowledge through the activities of these research councils.

Another major Engineering Foundation contribution was its efforts in the early 1960 s to establish the National Academy of Engineering. Through its broad perspective, organizational know-how, and the use of its funds, the Foundation served as a catalyst in the creation of this important institution.

The Engineering Foundation's primary focus during 1961 through 1975 was the establishment of Engineering Foundation conferences. Engineering Foundation conferences were initiated to promote discussions of new knowledge in engineering fields and to develop an interface with other disciplines. The conference format promotes discussion and enhances rapport among participants. These conferences have been instrumental in generating ideas and disseminating information in greater depth than is possible through most conventional presentations or publications. Approximately 25 conferences are held each year.

The conferences sponsored by the Engineering Foundation can be classified into four broad categories: 1. New Interdisciplinary Conferences - Conferences organized on a specific topic of current interest which involves a broad spectrum of the scientific and engineering community. Professional societies may have offered a session in one aspect of the topic at one of their traditional technical meetings. The success of these conferences depends on the ability of the Chair and Co-Chair to draw conference participants from a wide range of disciplines to discuss the topic in detail.

2. Continuing Interdisciplinary Conferences - Many of the successful new conferences give rise to one or more successor conferences on the same topic which are held on a one to three year schedule.

3. Technical Conferences - Conferences which deal with a specific topic which involves a single general research area and which may be co-sponsored by one or more of the professional societies.

4. Support Conferences - Conferences for which the Engineering Foundation serves as an umbrella support organization for one or more technical groups. 
Over 775 such conferences have been held on topics ranging from Corrosion Engineering to Professional Llability to Engineering in Medicine. The Engineering Foundation Conferences Committee is responsible for the planning, management, operation and evaluation of the conferences. Conferences are expected to be self-supporting on a yearly basis, but exact adherence to this goal is considered secondary to the objectives expressed above.

The Foundation's Conferences Director and staff provide administrative direction to the conference both from the New York office and at the various sites. The Conferences Director and staff are constantly engaged with the conference chairpeople, organizing committees, personnel at conference sites, and participants in their endeavor to make the conferences vital, rewarding and enjoyable.

Through its conferences and research grants, the Foundation became a pioneer in focusing the attention of the engineering community on such emerging areas of concern as urban mass transportation, pollution of the environment, and the technology gap between the Third World and the developed nations.

From 1976 through 1994 the Engineering Foundation sponsored its Engineering Research Initiation Grants (ERIG) program to support research by new faculty members in technical areas of interest to the Founder societies. It was designed not only to obtain solutions to technical problems but also to help attract and keep talented individuals on the academic staffs of university faculties. These grants also promoted early transfer of research findings to the engineering profession.

Currently almost all of the Foundation's discretionary income supports grant programs in three areas: Exploratory Research Grants, Advancement of Engineering Grants and the Engineering Journalism Award.

Altogether, some 250 leading engineers served as members of the Engineering Foundation Board. They were appointed as representatives of the Founder Societies (ASCE, AIME, ASME, IEEE, and AIChE), or of the United Engineering Trustees and its predecessors, or as members at large. Their, broad experiences and foresight resulted in judicious selection of projects and grant recipients, thus multiplying the effectiveness of the whole enterprise.

Founded by a visionary engineer-entrepreneur and guided by successive boards and directors of the highest caliber, the Engineering Foundation has been at the forefront of engineering research for 75 years. By building on this legacy, it is poised to continue to play.a catalytic role in the evolution of American science and technology.

Operations of the Foundation are overseen by a Board representing membership from the five Founder Societies of the UET. 
BOAS, DAVD A.

Assistant Professor

Massachusetts General Hospital

Radiology/NMR Center

CNY Building 149 13th Floor

Charfestown, MA 02129

Tel: 617-724-0130

Fax. 617-726-7422

E-mail: dboas@nmr.mgh.harvard.edu

BOONE, CHARLES $W$.

Program Director

National Institutes of Health

Cancer Chemoprevention Branch

6130 Executive Plaza Blvd.

Bethesda, MD 20892-7322

Tel: 301-594-0421

Fax: 301-594-2943

E-mail: boonec@dcpcepn.nci.nih.gov

BOVA, STEVEN

Johns Hopkins University

Medical Center

$600 \mathrm{~N}$. Wolfe Street

Baltimore, MD 21287

Tel: 410-614-5957

Fax: 410-614-8736

E-mail: gbov@jhmi.edu

CHALFIN, STEVEN

University of Texas

Ophthalmology Department

7703 Floyd Curt Drive

San Antonio, TX 78284-6230

Tel: 210-567-8411

Fax: 210-567-8413

E-mail: chalfin@uthscsa.edu

CHANCE, BRITTON

Professor Emeritus

University of Pennsylvania

Biochem/Biophysic Department

37th \& Hamilton, D501 R1C

Philadelphia, PA 19104-6089

Tel: 215-898-4342

Fax: 215-898-1806

E-mail: chance@mail.med.upenn.edu
BONNER, ROBERT F.

Chlef, Medical Biophysics

National Institute Health

Biomed Engr 2 Instr. Br.

Building 13, Room 3N17

Bethesda, MD 20892-5766

Tel: 301-435-1946

Fax: 301-435-5035

E-mail: bonner@helix.nih.gov

BORNHOP, DARRYL J.

Associate Professor

Texas Tech University

Chemistry \& Biochemistry Dept.

Box 41061

Lubbock, TX 79409-1061

Tel: 806-742-3142

Fax: 806-742-1289

E-mail: qzdjb@ttacs.ttu.edu

CARRERO, JENNY.

Bio-Optics Scientist

Unilever Research

45 River Road

Edgewater, NJ 07020

Tel: 201-840-2811

Fax: 201-840-8269

CHAN, KIN FOONG

Graduate Student

University of Texas

ENS 610

Austin, TX 78712

Tel: 512-471-9497

Fax: 512-475-8854

E-mail: kfchan@ccwf.cc.utexas.edu

CHEN, ZHONPING

Professor

University of California

Beckman Laser Institute

1002 Health Sciences Road, E.

Irvine, CA 92612

Tel: 949-824-1247

Fax: 949-824-8413

E-mail: zchen@bli.uci.edu 


\title{
ENGINEERING FOUNDATION CONFERENCES
}

\author{
Advances in Optics for Biotechnology, Medicine and \\ Kona Surf Hotel \\ Kona, Hawaii \\ August 01, 1999 to August 06, 1999
}

\section{PARTICIPANTS LIST}

A'AMAR, OUSAMA

Graduate Student

Los Alamos National Laboratory

MS E535

CST-4 Bioscience \& Biotech.

Los Alamos, NM 87545

Tel: 505-665-1190

Fax: 505-665-4637

ARNOLD, MARKA.

Professor

University of lowa

Department of Chemistry

230 lowa Advanced Tech. Labs.

lowa City, IA 52242

Tel: 319-335-1368

Fax: 319-335-1115

E-mail:mark-amold@uiowa.edu

BARGO, PAULO R.

Graduate Student

Oregon Graduate Institute

Medical Laser Center

9205 S.W. Bames Road

Portland, OR 97225

Tel: 503-216-6830

Fax: 503-216-2422

E-mail: pbargo@ece.ogi.edu

BERGER, ANDREW

University of California

Beckman Laser Institute

1002 Health Sciences Road, E.

Irvine, CA 92612

Tel: 949-824-4713

Fax: 949-824-8413

E-mail: ajberger@bli.uci.edu
ANDERSSON-ENGELS, STEFAN

Lund Institute of Technology

Physics Department

P.O. Box 118

S-221 00 LUnd, SWEDEN

Tel: $46-46-222-3121$

Fax: 46-46-222-4250

E-mail: stefan.andersson-engels@fysik.lth.se

BAER, THOMAS

President/CEO

Arcturus Engineering, Inc.

1220 Terra Bella

Mountain View, CA 94043

Tel: 650-962-3020

Fax: $650-962-3039$

E-mail: tmbaer@arctur.com

BEAUDRY, PIERRE

Executive Director

Att Advanced Research Tech.

2300 Boulevard Alfred Nobel

V.S.L.

Quebec H4S 2A4, CANADA

Tel: 514-832-0777

Fax: 514-832-0778

E-mail: pbeaudry@art.ca

BIGIO, IRVING J.

Senior Scientist

Los Alamos National Lab

Biosciences \& Biotechnology

CST-4, MS-535

Los Alamos, NM 87545

Tel: 505-667-7748

Fax: 505-665-4637

E-mail: jjb@LanL.gov 
CHEONG, WAI-FUNG

Director, Bioengineering

Pharmacyclics

995 East Arques Avenue

Sunnyvale, CA 94086

Tel: 408-774-3357

Fax: 408-774-0340

E-mail:wcheong@pctc.com

\section{CHOE, REGINE}

Graduate Student

University of Pennsylvania

Physics Department

209 South 33rd Street

Philadelphia, PA 19104

Tel: 215-898-3296

Fax: 215-898-1806

E-mail: rgchoe@mail.sas.upenn.edu

COFFEY, DONALD $S$.

Professor

Johns Hopkins University

Urology Department

600 North Wolfe Street

Baltimore, MD 21287

Tel: 410-955-2517

Fax: 410-955-0833

\section{COLSTON, BILL}

Lawrence Livermore Nat'l. Lab.

7000 East Avenue

Livermore, CA 94550.

Tel: 925-423-0375

Fax: 925-424-2778

E-mail: colston1@llnl.gov

CULVER, JOSEPH P.

Post Doctoral Fellow

University of Pennsylvania

Physics \& Astronomy Dept.

209 South 33rd Street

Philadelphia, PA 19130

Tel: 215-573-3463

Fax: 215-573-6391

E-mail: culver@sol1.Irsm.upenn.edu
CHEUNG, CECIL

University of Pennsylvania

Physics Department

Philadelphia, PA 19104

Tel: 215-573-3463

Fax: 215-573-6391

E-mail: cheung@dept.physics.upenn.edu

CHOI, BERNARD

University of Texas

Biomedical Engineering Program

ENS Building, Room 610

Austin, TX78712-1084

Tel: $512-471-3619$

Fax: 512-475-8854

E-mail: berniec@mail.utexas.edu

COLENO, MARIAH L.

Graduate Student

University of California

Beckman Laser Institute

1002 Health Sciences Road, E.

Irvine, CA 92612

Tel: 949-824-4713

Fax: 949-824-8413

E-mail: mcoleno@bli.uci.edu

CONTAG, CHRISTOPHER H.

Assistant Professor

Stanford University

School of Medicine

300 Pasteur Drive

Stanford, CA 94305-5208

Tel: 650-723-0707

Fax: 650-498-7723

E-mail: ccontag@cmgm.stanford.edu

DELPY, DAVID T.

Professor

University College London

Medical Physics \& Bioengrg.

Shropshire House, 11-20 Capper

London, WC1E 6JA, UNITED KINGDOM

Tel: 44-171-209-6262

Fax: 44-171-209-6269

E-mail: d.delpy@medphys.ucl.ac.uk 


\section{DREZEK, REBEKAH A.}

Graduate Studẹnt

- University of Texas

Biomedical Engineering Program

26th \& San Jacinto, ENS 610

Austin, TX78712-1084

Tel: $512-471-3619$

Fax: 512-475-8854

E-mail: drezek@ece.utexas.edu

DURDURAN, TURGUT

University of Pennsylvania

Physics \& Astronomy Dept.

209 South 33rd Street, DRL

Philadelphia, PA 19104

Tel: 215-573-3463

Fax: 215-573-6391

E-mail: durduran@mail.sas.upenn.edu

\section{ERLANDER, MARK G.}

R.W. Johnson Pharmaceuticals

3535 General Atomics Court

Suite 100

San Diego, CA 92121

Tel: 858-450-2075

Fax: 858-450-2040

E-mail: erlanderm@prius.jnj.com

FARKAS, DANIEL L.

Professor

University of Pittsburgh

Department of Bioengineering

434 South Dallas Avenue

Pittsburgh, PA 15208

Tel: $412-268-6460$

Fax: 412-268-6571

E-mail: farkas+@cmu.edu

FITZMAURICE, MARYANN

Staff Pathologist

University Hospitals

Case Westem Reserve Univ.

11100 Euclid Avenue

Cleveland, OH 44106

Tel: 216-844-5228

Fax: 216-844-1810

E-mail: msf39@po.cwru.edu

\section{DUGROS, MATHIEU G.}

University of Texas

Biomedical Engineering Program

Bullding ENS, Room 610

Austin, TX78712

Tel: $512-471-4703$

Fax: 512-475-8854

E-mail: mathieu_ducros@mail.utexas.edu

EKER, CHARLOTTA

Lund University

Physics Department

P.O. Box 118

Lund SE-221 00, SWEDEN

Tel: $46-46-222-3120$

Fax: $46-46-222-4250$

E-mail: lotta@fysik.Ith.se

\section{FANTINI, SERGIO}

Research Assistant Professor

University of Illinois

Physics Department

1110 West Green Street

Urbana, IL 61801

Tel: 217-244-5620

Fax: 217-244-7187

E-mail: fantini@uiuc.edu

FELD, MICHAEL

Director

M.I.T.

Harrison Spectroscopy Lab

77 Massachusetts Ave. Rm 6-014

Cambridge, MA $02139-4307$

Tel: 617-253-7700

Fax: 617-253-4513

E-mail: msfeld@mit.edu

FOLLEN-MITCHELL, MICHELE

MD Anderson Cancer Center

1515 Holcombe Blvd.

Box. 0067

Houston, TX 77030

Tel: 713-745-2564

E-mail: mmitchel@mdanderson.org 
FULGHUM, STEPHEN F.

Vice President, Technology

- Newton Laboratories, Inc. 800 West Cummings Park

Sulte 4850

Wobum, MA 01801

Tel: 781-933-2111

Fax. 781-933-7555

E-mail: sfulghum@tiac.net

GARDNER, CRAIG

Research Scientist

Rio Grande Medical Tech., Inc.

108 Sewall Avenue

Apartment 3

Brookline, MA 02446

Tel: 617-277-7576

Fax: 505-272-4634

E-mail: gardner@rgmt.com

GLICKMAN, RANDOLPH D.

Associate Professor

University of Texas

Ophthalmology Department

7703 Floyd Cart Drive

San Antonio, TX 78284-6230

Tel: $210-567-8420$

Fax: 210-567-8413

E-mail: glickman@uthscsa.edu

HANLON, EUGENE B.

Research Scientist

M.I.T.

77 Massachusetts Avenue, 6-014

Cambridge, MA 02139

Tel: 617-253-5077

Fax: 617-253-4513

E-mail: ebhanlon@mit.edu

\section{HAWRYSZ, DANIEL}

Graduate Student

Purdue University

1283 CHME

West Lafayette, IN 47907

Tel: 765-496-2739

Fax: 765-494-0805

E-mail: hawrysz@ecn.purdue.edu
FURLONG, STEVEN

Chief Technology Officer

Ltfe Spex, Inc.

11335 NE 122nd Way

Suite 175

Kirkland, WA 98034

Tel: 425-820-6225

Fax: 425-820-2660

E-mail: furlong@lifespex.com

GEORGAKOUDI, IRENE

M.I.T.

Spectroscopy Laboratory

77 Massachusetts Avenue

Cambridge, MA 02139

Tel: 617-258-9487

Fax. 617-258-6586.

E-mail: ireneg@mit.edu

GURJAR, RAJAN S.

Research Fellow

M.I.T.

Spectroscopy Laboratory

Vassar Street, 6A-230

Cambridge, MA 02139

Tel: 617-258-7831

Fax: 617-253-4513

E-mail: rajn@mit.edu

HASAN, TAYYABA

Associate Professor

Harvard Medical School

Massachusetts General Hospital

Dermatology Department

Boston, MA 02114

Tel: 617-726-6996

Fax: 617-726-3192

E-mall: hasan@helix.mgh.harvard.edu

HELL, STEFAN

Head, High Resolution Optical

Max Planck Institute

Biophysical Chemistry

Am Fassberg 11

D-37077 Goettingen, GERMANY

Tel: 49-551-201-1366

Fax: 49-551-201-1085

E-mail: shell@gwdg.de 


\section{HERMANN, MARCUS}

- Graduate Student

- Roche Diagnostics GmbH

166 King Street, W.

Apt 4

Hamilton Ontario, CANADA

Tel: 905-540-4890

Fax: 905-575-6330

E-mail: marcus.hermann@hrcc.on.ca

HILL, JOHN S.

Miravant Medical Technologies

Medical Research Department

336 Bollay Drive

Santa Barbara, CA 93117

Tel: 805-685-9880

Fax: 805-685-2829

E-mail: Jhill@miravant.com

JACQUES, STEVEN L.

Oregon Medical Laser Center

9205 S.W. Bames Road

Portland, OR 97225

Tel: 503-216-4092

Fax: 503-216-2422

E-mail: sjacques@ee.ogi.edu
HIELSCHER, ANDREAS H.

Assistant Professor

SUNY Health Sclence Center

Pathology Department

450 Clarkson Avenue, Box 25

Brooklyn, NY 11203

Tel: 718-270-4562

Fax: 718-270-3313

E-mail: ahielscher@netmail.hscbklyn.edu

HILLENKAMP, FRANZ

Professor

Universitat Munster

Institute fur Med. Physik

Robert Koch Str. 31

D-48149 Munster, GERMANY

Tel: 49-251-835-5103

Fax: 49-251-835-5121

E-mail: hillenk@uni-muenster.de

KEISER, L. WAYNE

Director, Medical Research

Redwood Regional Medical Group

3555 Round Barn Circle, \#100

Santa Rosa, CA 95403

Tel: 707-528-1050

Fax: 707-525-3874

KILLINGER, DENNIS K.

University of South Florida

Dept of Physics

Tampa, FL 33620

Tel: 813-974-3995

Fax: 813-974-2635

E-mail: killinge@chuma.cas.usf.edu

\section{KRASIEVA, TATIANA B.}

Associate Specialist

University of California

Beckman Laser Institute

1002 Health Sciences Road, E.

Invine, CA 92612

Tel: $949-824-3664$

Fax: 949-824-8413

E-mail: tkrasiev@bli.uci.edu 
LAMORTE, VICKIE J.

Assistant Professor

University of California

Beckinan Laser Institute

1002 Health Sciences Road, E.

Irvine, CA 92612

Tel: 949-824-3513

Fax: 949-824-8413

E-mail: lamorte@bli.uci.edu

\section{LANDINEZ, ROSA}

UEF Staff

United Engineering Foundation

3 Park Avenue

27th Floor

New York, NY 10016-5902

Tel: 212-591-7836

Fax: 212-591-7441

E-mail: engfnd@aol.com

MAITLAND, DUNCAN J.

Group Leader

Lawrence Livermore Nat'I. Lab.

700 East Avenue

L-339

Livermore, CA 94550.

Tel: 925-423-6697

Fax: 925-424-2778

E-mail: dmaitland@llnl.gov

MOURANT, JUDITH R.

Los Alamos National Lab

CST-4, MS E535

P.O. Box 1663

Los Alamos, NM 87545

Tel: 505-665-1190

Fax: 505-665-4637

E-mail: jmourant@lanl.gov

NTZIACHRISTOS, VASILIS

University of Pennsylvania

D501 Richards Building

Philadelphia, PA 19104-6089

Tel: 215-898-4342

Fax: 215-898-1806

E-mail: vasilis@mail.med.upenn.edu
LAM, STEPHEN

Professor

University of British Columbia

Medicine Department

2775 . Heather Street

Vancouver V5Z 3J5, CANADA

Tel: 604-876-4325

Fax: 604-875-5799

E-mail: sclam@interchange.ubc.ca

LOTEM, HAIM

NRCN

74 Shita Street

P.O. Box 402

Omer 84965, ISRAEL

Tel: 972-7-656-7721

Fax: 972-7-656-8770

E-mail: lotem@iname.com

MAJARON, BORIS

University of Califomia

Beckman Laser Institute

1002 Health Sciences Road, E.

Irvine, CA 92612-1475

Tel: 949-824-4178

Fax: 949-824-8413

E-mail: majaron@bli.uci.edu

NORDSTROM, ROBERT J.

Vice President, Research

MediSpectra, Inc.

125 Hartwell Avenue

Lexington, MA 02421

Tel: 781-674-0001

Fax: 781-674-0002

E-mail: robertn@madispectra.com

ORAEVSKY, ALEXANDER A.

Assistant Professor

University of Texas

301 University Boulevard

MS 0456

Galveston, TX 77555

Tel: 409-772-8348

Fax: 409-772-0751

E-mail: aaoraevs@utmb.edu 
PATTERSON, MICHAEL S.

Head of Medical Physics

- Hamilton Cancer Centre

699 Cóncession Street

Hamilton, Ontario L8V 5C2, CANADA

Tel: 905-387-9711

Fax: 905-575-6330

E-mail: mike_patterson@hrcc.on.ca

PFEFER, T. JOSHUA

Graduate Student

University of Texas

Biomedical Engineering Program

ENS 610

Austin, TX78712

Tel: $512-471-4703$

Fax: 512-475-8854

E-mail: pfefer@ccwf.cc.utexas.edu

PRAHL, SCOTT A.

Associate Professor

Oregon Health Sciences Univ.

9205 S.W. Bames Road

Portland, OR 97225

Tel: 502-216-2197

Fax: 502-216-2422

E-mail: prahl@ece.ogi.edu

RICHARDS-KORTUM, REBECCA R.

Associate Professor

University of Texas

Electrical \& Computer Eng.

Room 8, Eng. Science Bldg.

Austin, TX 78712

Tel: 512-471-7827

Fax: 512-471-0616

E-mail: kortum@mail.utexas.edu

ROEDERER, MARIO

UCSF

C634C

521 Parnassus Avenue

San Francisco, CA 94143

Tel: 415-514-0395

Fax: 415-476-4204

E-mail: roederer@drmr.com
PERELMAN, LEVT.

Principal Research Scientist

M.I.T.

Harrison Spectroscopy Lab

77 Massachusetts Avenue

Cambridge, MA 02139-4307

Tel: 617-258-7095

Fax. 617-253-4513

E-mail: Itperep@mitedu

POGUE, BRIAN

Research Assistant Professor

Dartmouth College

Thayer School of Engineering

8000 Cummings Hall

Hanover, NH 03755-8000

Tel: 603-646-3861

Fax. 603-646-3856

E-mail: pogue@dartmouth.edu

\section{RAJADHYAKSHA, MILIND}

MA General Hospita!

Dermatology Department

Barlett Hall Ext. 630

Boston, MA 02114

Tel: 617-724-3955

Fax: 617-724-2075

E-mail: rajadmil@helix.mgh.harvard.edu

RIPLEY, PAUL M.

Postdoc Research Associate

Los Alamos National Lab.

Bioscience \& Biotechnology

CST-4, MS-E535, LANL

Los Alamos, NM 87545

Tel: 505-667-4663

Fax: 505-665-4637

E-mail: pripley@lanl.gov

SANKARAN, VANITHA

Graduate Student

Lawrence Livermore Nat'I Lab.

7000 East Avenue

L-399

Livermore, CA 94551

Tel: 925-424-3101

Fax: 925-424-2778

E-mail: sankaran1@llnl.gov

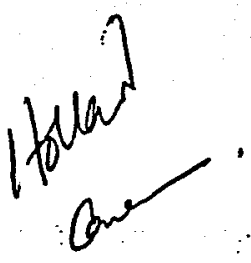




\section{SATHYAM, UNWAL S.}

Lawrence Livermore Natl. Lab.

iP. O, Box 808

$$
\text { L-399' }
$$

Livermore, CA 94551

Tel: 925-424-3521

Fax: 925-424-2778

E-mail: ujwal@linl.gov

SOKOLOV, KONSTANTIN V.

Research Associate

University of Texas

Biomedical Engineering

ENS 123

Austin, TX 78712

Tel: 512-471-7440

Fax: 512-475-8854

E-mail: kostia@mail.utexas.edu

STOTT, CHARLES B.

Charles B. Stott Associates

PC Specialists

9020 East Palms Park Drive

Tucson, AZ 85715-5645

Tel: 520-296-2769

Fax: 520-296-2769

E-mail: charlesstott@ieee.org

TOSTO, SEBASTLANO

ENEA Casaccia

via Anguillarese 301

00060 Rome, ITALY

Tel: 39-06-3048-3338

Fax: 39-06-3048-4729

E-mail: tosto@casaccia.enea.it

\section{UTZINGER, URS}

University of Texas

Biomedical Engineering Program

Austin, TX 78712

Tel: 512-471-2398

Fax: 512-471-0616

E-mail: utzinger@mail.utexas.edu
SEVICK-MURACA, EVA M.

Associate Professor

Purdue University

School of Chemical Engineering

West Lafayette, IN 47907

Tel: 765-496-2377

Fax. 765-494-0805

E-mail: sevick@ecn.purdue.edu

SPOTT, THORSTEN

Graduate Student

NTNU/University of Califomia

Beckman Laser Institute

1002 Health Science Road, E.

Irvine, CA 92612

Tel: $949-824-4712$

Fax: 949-824-8413

E-mail: thorsten@fysel.ntnu.no

STRONG, ANDREW

Director, Clinical Research

QLT PhotoTherapeutics, Inc.

520 West 6 th Avenue

Vancouver

British Columbia V5Z 4H5, CANADA

Tel: 604-872-7881

Fax: 604-875-0001

E-mail: astrong@qlt-pdt.com

TROMBERG, BRUCE J.

University of California

Beckman Laser Institute

Irvine, CA 92612

Tel: 949-824-8705

Fax: 949-824-8413

E-mail: tromberg@nova.bli.uci.edu

\section{VANSLYKE, STEPHEN}

Research Scientist

Rio Grande Medical

800 Bradbury SE, \#217

Albuquerque, NM 87106

Tel: 505-272-7246

Fax: 505-272-7112

E-mail: stephenv@rgmt.com 
VARGAS, GRACIE

Graduate Student

- Universily of Texas

Biomédical Engineering

ENS 610

Austin, TX 78741

Tel: 512-471-4703

Fax. 512-475-8854

E-mail:.gvargas@mail.utexas.edu

VSURI, STEVEN R.

Research Scientist

Lawrence Livermore Nat'l Lab.

P.O. Box 808; L-399

Livermore, CA 94551

Tel: 925-424-3517

Fax: 925-424-2778

E-mail: visuri@llnl.gov

WAYNANT, RONALD W.

Medical Research Officer

Food and Drug Administration

Electro-Optics Branch

MS HFZ-134 12725 Twinbrook

Rockville, MD 20857

Tel: 301-827-4688

Fax: 301-827-4677

E-mail: ron@eob.cdm.fda.gov

WONG, BRIAN J.

Assistant Professor

University of California

Beckman Laser Institute

1002 health Sciences Road, E.

Invine, CA 92612

Tel: $949-824-6996$

Fax: 949-824-8413

E-mail: bjiwong@bli.uci.edu

YODH, ARJUN G.

Professor

University of Pennsylvania

Physics \& Astronomy Dept.

209 South 33rd Street

Philadelphia, PA $19104-6396$

Tel: 215-898-6354

Fax: 215-898-2010

E-mail: yodh@dept.physics.upenn.edu
VERKRUYSSE, WMM

University of Califomia

Beckman Laser Institute

1002 Health Sciences Road, E.

Irvine, CA 92612

Tel: $849-824-4770$

Fax: 949-824-8413

E-mail: wverkru@bli.uci.edu

\section{WALLACE, VINCENT}

Graduate Student

Beckerman Laser Institute

1002 Health Science Road, East

Irvine, CA 82612

Tel: $949-824-4713$

Fax: 949-824-8413

E-mail: wwallace@bli.uci.edu

\section{WLSON, TONY}

Professor, Engineering Science

University of Oxford

Engineering Science Dept.

Parks Road

Oxford OX1 3PJ, UNITED KINGDOM

Tel: 44-1865-273-116

Fax: 44-1865-273-905

E-mail: tony.wilson@eng.ox-ac.uk

WOODBURN, KATHRYN

Pharmacyclics

995 E. Arques Avenue

Sunnyvale, CA 94086

Tel: 408-774-0330

Fax: 408-774-0340

E-mail: kathy@pcyc.com

\section{ZULUAGA, ANDRES F.}

Graduate Student

University of Texas

Biomedical Engineering Program

24th \& Speedway Streets

Austin, TX 78705

Tel: $512-471-4703$

Fax: 512-475-8854

E-mail: a.f.zuluaga@mail.utexas.edu 